\title{
Psychological barriers in oil futures markets
}

\author{
Michael Dowling a,*, Mark Cummins ${ }^{\text {a }}$, Brian M. Lucey ${ }^{\text {b,c,d }}$ \\ a DCU Business School, Dublin City University, Dublin 9, Ireland \\ b Business School and Institute for International Integration Studies, Trinity College Dublin, Dublin 2, Ireland \\ c Glasgow School for Business, Glasgow Caledonian University, Scotland, UK \\ d University of LjubljanaFaculty of EconomicsKardeljeva Ploščad 171000 Ljubljana, Slovenia
}

\section{A R T I C L E I N F O}

\section{Article history:}

Received 20 September 2013

Received in revised form 24 February 2014

Accepted 25 March 2014

Available online $\mathrm{xxxx}$

\section{JEL classification:}

G15

013

Q43

Keywords:

Psychological barriers

Clustering

WTI

Brent

Multiple hypothesis testing

\begin{abstract}
A B S T R A C T
WTI and Brent futures are tested for the presence of psychological barriers around \$10 price levels, applying a multiple hypothesis testing approach for statistical robustness. Psychological barriers are found to be present in Brent prices but not in WTI prices, which is argued to be due to the more prominent role that Brent plays as a global benchmark and, based on recent behavioural finance research, the greater complexity inherent in Brent fundamental value determination. Brent particularly displays evidence that when breaching a $\$ 10$ barrier level from below with rising prices, the trend is for prices to fall on average subsequently. Similar behavioural-based patterns are evidenced at the \$1 barrier level for the WTI-Brent spread. We show that psychological barriers only appear to influence prices in the pre-credit crisis period of 1990-2006, with such effects dissipating during the crisis and as markets reverted back to wider economy focused fundamentals. A range of reaction windows are applied with the main finding being that the trading potential around such psychological barrier levels is primarily in the immediate 1-5 days following a breach. The research contributes to the scant existing research on psychological influences on energy market traders, and suggests strong potential for further application of behavioural finance theories to improving understanding of energy markets price dynamics.
\end{abstract}

(c) 2014 Elsevier B.V. All rights reserved.

\section{Introduction}

Recent research by Narayan et al. (2011) investigates price clustering in oil futures and finds significant evidence of clustering in these contracts particularly around whole dollar amounts (i.e. prices with digits ending in .00). Further recent research by Bharati et al. (2012) finds clustering in whole dollar amounts ending in the 9 digit in NYMEX oil contracts. These findings contradict the notion of pricing efficiency, which would suggest that prices evolve in a manner where the likelihood of any given price change is approximately equal. This would in turn result in the distribution of "trailing" digits (the last digit of a price) following either a uniform distribution of digits or a distribution following Benford's Law (see Bharati et al., 2012) and thus there would be no systemic clusters of prices around digits. In contrast to this theory, a number of alternative price dynamic theories have been suggested, particularly a price attention and attractiveness hypothesis, developed based on psychological principles and empirical observations of trader and price behaviour, which suggests that traders

\footnotetext{
* Corresponding author.

E-mail addresses: michael.dowling@dcu.ie (M. Dowling), Mark.Cummins@dcu.ie (M. Cummins), blucey@tcd.ie (B.M. Lucey).
}

pay particular attention to certain price points and are naturally drawn to whole number prices thus leading to price clustering. This clustering behaviour has been observed across a range of financial markets, including equity markets (Bhattacharya et al., 2012; Ikenberry and Weston, 2008), gold pricing (Aggarwal and Lucey, 2007) and carbon markets (Palao and Pardo, 2012).

In this paper, we extend the price clustering testing in oil futures markets by testing for the presence of psychological barriers in prices. Psychological barriers can be viewed as a partial explanation for clustering, as it is posited that prices cluster around certain digits due to traders' differential perspectives of prices around psychologically important price points such as whole dollar or tens of dollar prices, compared to nonpsychologically important price points (Mitchell, 2001). An important advance on price clustering is that psychological barriers focus on price directional movements around barrier regions and is thus of particular relevance to informing trading behaviour. Psychological barriers have been previously observed in equity markets (Bhattacharya et al., 2012; Ikenberry and Weston, 2008), and more relevantly, in markets primarily traded by professional traders, such as foreign exchange (Westerhoff, 2003) and gold (Aggarwal and Lucey, 2007). Thus, for example, Aggarwal and Lucey (2007) find the presence of psychological barriers in the 100 s digits of gold prices (e.g. $\$ 200, \$ 300, \ldots$ ) with, amongst other 
findings, significant differences in price behaviour before and after breaching a barrier point from below.

Our study investigates the presence of psychological barriers in the prices of WTI and Brent futures over the time period 1990-2012. This is motivated by the prior finding of price clustering in oil futures, given the aforementioned overlap between clustering and psychological barriers. The presence of psychological barriers in other markets primarily traded by professional traders provides a further impetus for the study. This research partially addresses the paucity of studies involving the application of psychological bias theories to energy futures markets, despite their widespread application in other financial markets. A traditional explanation for this lack of research is the view that psychological factors should mainly influence the investment decisions of small investors (usually in equity markets) who are most likely to be boundedly-rational in their decision making due to limited appropriate knowledge and limited ability to process that knowledge (DeLong et al., 1990). Given that energy futures are primarily traded by professional market participants there should be a limited role for psychological influences in their trading behaviour according to this perspective. This view has been challenged by recent professional market participant studies. For example, intra-day trading patterns of Chicago Board of Trade (CBOT) traders show loss aversion influencing decision making (Coval and Shumway, 2005), the trading decisions of currency traders display overconfidence (O'Connell and Teo, 2009), and current trading decisions are subject to sensitivity to past portfolio losses (Froot et al., 2011). Further, a recent qualitative study by Fenton-O'Creevy et al. (2011) of 118 UK-based professional traders in equity, bond, and derivatives markets finds that traders allow emotions to influence their trading decision making in a manner that deviates from purely rational decision-making. This suggests that it is unlikely that oil futures market participants will be immune to psychological bias influences on their trading behaviour.

More generally, studies of price dynamics in energy markets remain relatively sparse compared to equivalent studies in the financial markets. The reason for this is in no small part due to the very distinctive features of the energy markets, in particular the less than complete transparency of physical markets and the lack of liquidity for many derivatives contracts (Swierenga, 2012). A better understanding of price dynamics in energy markets is of interest to market participants, regulators and researchers, and this is motivated by the need to appraise the influence of exchange based and over-the-counter based trading activity on long-term physical contracts (Swierenga, 2012). Furthermore, the "financialization" of energy markets has become an ever-growing topic of interest for industry participants and academics alike. This is the central focus of a recent 2012 report from the United Nations Conference on Trade and Development, for instance. ${ }^{1}$ and some were made 15 or more years ago. Increased financial trading activity and participation by financial market actors (such as institutional investors and hedge funds) has become a feature of energy and, more broadly, commodity markets in recent years. Panella et al. (2014) point to the increase in global commodity assets under management from $\$ 10$ billion in 2001 to $\$ 400$ billion in 2011, the generation of $\$ 5$ billion annually in banking fees from commodity investment activity since 2005 and the observation by Ghalayini (2011) that WTI trading volume has increased from $130 \%$ of US oil demand in 1990 to $700 \%$ of US oil demand in 2011. Much debate abounds on the extent and effect of speculative trading on energy markets, with increased recent research output on the topic (Acharya et al., 2013; Fattouh and Mahadeva, 2012; Hache and Lantz, 2013; Tokic, 2011). While, Fattouh and Mahadeva (2012) argue that there are data availability issues in researching the effect, there is some recent research suggesting that the presence of speculative traders is linked

United Nations Conference on Trade and Development, 2012. Price formation in financialized commodity markets: The role of information. Technical Report, available from: http://unctad.org/en/Docs/gds20111_en.pdf. to behaviour in the pricing of oil futures (Acharya et al., 2013). Thus, while tentative, the financialization hypothesis suggests an avenue by which biases in professional trader behaviour known to exist in other markets might also be present in oil futures markets.

The examination, in this study, of psychological influences in energy prices adds in a unique way to the price dynamics literature, with the identified evidence of psychological barriers influencing prices providing insights into speculative effects on price that deviate from the market fundamentals of supply and demand. While there are clear trading implications from such a finding (and indeed timing implications for industry participants who use the market for hedging purposes), a finding of the presence of psychological barriers also opens the oil futures market to further investigation for the presence of other psychologically-derived price theories. We significantly expand on the previous approaches to testing psychological barriers through a number of theoretical and testing advances that offer novel perspectives on how psychological barriers are likely to influence oil futures prices. Focusing on $\$ 10$ barrier regions (movements through a whole price number ending in a 0 dollar digit), we show that psychological barriers only appear to influence prices in the period 1990-2006, where prices traded within a lower range of approximately $\$ 10-\$ 78$, relative to the $2007-2012$ period. The choice to split the data at the 2006-2007 juncture is made to capture the peak in oil prices at $\$ 145 / \$ 146$ per barrel in 2007 and the resulting collapse in oil prices from 2008 with the emergence of the credit crisis. The split is also driven by the finding of De Zwart et al. (2009) that when markets are strongly driven by fundamentals, as during the 2007-2012 oil market, traders tend to switch to fundamental pricing models, leaving minimal scope for influence from psychological barriers. Significant focus is also placed on determining the speed of market reaction to barrier breaches, with reaction time periods from 1 day to 2 weeks tested. This has traditionally been ignored in the psychological barriers literature but has potential trading implications.

We further distinguish between Brent and WTI contracts on the grounds that recent evidence suggests that Brent has surpassed WTI to become a more prominent global price reference and that there is inherently greater complexity in determining fundamental value for Brent. On the former point, Fattouh (2011) suggests that WTI is a broken benchmark and points to the more recent outflow bottleneck issues that have prevailed around the Cushing storage point. Indeed, this bottleneck has led in recent years to downward pressure on WTI prices, with markets trading the crude oil at a significant discount to Brent. Kao and Wan (2012) likewise highlight that over recent years WTI has failed to reflect market conditions and point again to the close link between price and inventory levels at Cushing, while they also propose that Brent has surpassed WTI as the leading reference price since 2004. Jin et al. (2012) demonstrate that Brent is responsive to global price shocks while WTI appears to be increasingly disconnected from such shocks. This dislocation between WTI and Brent has also been argued previously by Bentzen (2007), Hammoudeh et al. (2008) and Kaufmann and Ullman (2009), with Fattouh $(2007,2009,2010)$ discussing the Cushing inventory effect on WTI. The emergence of Brent as the leading global benchmark in the crude oil markets is reflected in estimates that approximately $70 \%$ of international trade is priced directly or indirectly off Brent (Fattouh, 2011). This leading benchmark role for Brent over WTI we argue may explain the greater psychological barrier effects that we find in Brent futures prices.

Drawing on recent advances in behavioural finance showing an increased role for psychological biases in more complex decisions (e.g. Dowling and Lucey, 2008; Yao and Li, 2013), we argue further that the greater complexity surrounding Brent fundamental value leads to a greater role for psychological barriers in price formation for futures contracts. The complexity of Brent over WTI is reflected in the many more layers and financial instruments that exist within the Brent pricing system, spanning dated Brent, Brent forwards, Contract for Differences (CfDs), Exchange for Physicals, and Brent 
futures, options and swaps (Fattouh, 2011). We argue in the conclusions section that this complexity-driven perspective on psychological influences offers significant potential as a framework for future similar studies in energy markets. The statistical support for these conclusions is strengthened by our application of generalised multiple hypothesis testing approaches to minimise the potential for false discoveries in our multiplicity of testing - a problem commonly referred to as the multiple comparisons problem in statistical literature. Controlling for the multiple comparisons problem as we do in this study allows us to make statistically robust conclusions on the psychological barrier effects in crude oil markets and forms a final key advancement of the literature.

\section{Methodology and data}

The main testing approach is an adaptation of Aggarwal and Lucey (2007) and involves two groups of tests: (i) barrier tests, which are akin to price clustering analyses, and (ii) tests of conditional effects. Barrier tests consist of proximity and kurtosis tests. Barrier proximity tests examine whether digits close to a hypothesised psychological barrier show abnormal frequencies and thus act as a test of price clustering without necessarily investigating the prices around which clustering happens, while barrier kurtosis (also known as barrier hump) tests examine whether there is a significantly different frequency distribution around the numbers being investigated. Tests of conditional effects consider a range of possible different reactions to the particular barrier condition; e.g. whether a price is approaching a barrier point from below or above, and whether the price is approaching a barrier or whether the barrier has been passed. The barrier tests are described next and the tests of conditional effects are outlined in Section 2.2.

\subsection{Barrier tests: evidence for clustering}

Barrier proximity tests are designed to measure whether or not price observations on or near barriers occur significantly less frequently than a uniform distribution would predict. In general, these tests examine the shape of the frequency distribution for various decimal digit combinations. The tests of this paper examine the presence of $\$ 10$ and $\$ 1$ psychological barriers, which we label for convenience as "10s" and "1s" levels respectively. 10s psychological barrier tests are designed to examine the two digits bracketing the decimal point and 1s psychological barrier tests are designed to examine the two digits to the immediate right of the decimal point. An expectation based on prior studies is that barriers are most likely to exist at exact tens of dollars, such as $\$ 100$ for example, so there should be higher frequency in the 10 s of 00 digits compared to other digits. A similar finding is expected around 00 digits in the $1 \mathrm{~s}$ tests, which denotes whole dollar price amounts. For the barrier tests in this study, a barrier range is defined rather than applying the tests to a strict barrier of 00 . The barrier ranges considered for study are set out below but taking the $\$ 100.00$ level for instance then we are interested in prices that surround this level, such as $\$ 99.8 \mathrm{x}, \$ 99.9 \mathrm{x}, \$ 100.1 \mathrm{x}$ and $\$ 100.2 \mathrm{x}$. Following the definition that the 10 s barriers bracket the decimal point, the digit combinations of interest would be 98, 99, 01 and 02 respectively. Turning attention now to the $1 \mathrm{~s}$ barriers, take for instance a price level transition from $\$ 103 . x x$ to $\$ 104 . x x$. In this case, we are interested in prices such as $\$ 103.98, \$ 103.99, \$ 104.01$ and $\$ 104.02$ and so following the definition of the $1 \mathrm{~s}$ barriers as being the two digits to the immediate right of the decimal point, the digit combinations of interest would again be $98,99,01$ and 02 respectively.

In this context, we define $M$ to be the set of all digits $\{0, \ldots, 99\}$. Three barrier ranges are defined as follows: $B R^{1} \equiv\{98,99,00,01,02\}, B R^{2} \equiv\{95$, $\ldots, 00, \ldots, 05\}$ and $B R^{3} \equiv\{90, \ldots, 00, \ldots, 10\}$, all of which are centred on 00. Each of the defined barriers is then represented by a dummy variable, $D^{i}, i=1,2,3$, taking a value of 1 for digits in the barrier range and 0 otherwise, with the specific equation tested being:

$$
f(M)=\alpha+\beta D^{i}+\varepsilon,
$$

where $f(M)$ is the absolute frequency of digits. The test for barriers then amounts to a test of significance of the coefficient on the dummy variable. Under the null of no barriers $\beta$ will be zero, whereas the presence of barriers will result in a higher frequency of M-values at the barrier and thus $\beta$ will be positive and significant.

The barrier kurtosis tests examine whether there is a significantly different frequency distribution shape around the barrier points and takes the testing form:

$f(M)=\alpha+\varphi M+\gamma M^{2}+\varepsilon$,

with the frequency of the M-digits being regressed on both their values and the square of their values. If there is no abnormal distribution shape around barrier points then the coefficient of $\gamma$ should have a value of 0 , while the presence of an abnormal barriers shape would be suggested by a significant negative coefficient and clustering would be shown in a significant positive coefficient.

\subsection{Tests of conditional effects: psychological barriers}

A range of possible conditional effects are further tested to determine if there is a differential reaction depending on the conditions related to the psychological barrier; such as whether the barrier is being approached by rising prices or by falling prices, or other relevant conditions that might conceivably influence reaction. An example from a prior study of how condition might influence professional trader behaviour comes from Coval and Shumway (2005), who find that professional trader performance in CBOT during a morning trading period influences risk attitudes and levels of loss aversion in afternoon trading sessions i.e. afternoon trading is conditioned on morning trading. Our initial test is an OLS regression with dummy variables based on whether barriers are (i) being approached or (ii) after being breached, and also whether a barrier is reached through rising or falling prices. This necessitates setting up the following four dummy variables:

- $B D B^{n}$, which assigns 1 to the $n$ days before a downward breach, i.e. a barrier breach from above due to downward or falling prices;

- $A D B^{n}$, which assigns 1 to the $n$ days after a downward breach, i.e. a barrier breach from above due to downward or falling prices;

- $B U B^{n}$, which assigns 1 to the $n$ days before an upward breach, i.e. a barrier breach from below due to upward or rising prices;

- $A U B^{n}$, which assigns 1 to the $n$ days after an upward breach, i.e. a barrier breach from below due to upward or rising prices.

These dummy variables are regressed against returns in order to determine whether the periods covered by each dummy are associated with anomalous behaviour. Specifically, the following regression model is considered:

$R_{t}=\beta_{0}+\beta_{1} R_{t-1}+\beta_{2} B D B_{t}^{n}+\beta_{3} A D B_{t}^{n}+\beta_{4} B U B_{t}^{n}+\beta_{5} A U B_{t}^{n}+\varepsilon_{t}$.

To test the speed of market reaction to barrier breaches, we consider a range of reaction windows of size $n$ days. Specifically, we choose $n=$ $1,2,3,4,5$ and 10 days, which allows us to assess the speed of market reaction over and up to the week before and the week after a barrier breach but also, for comparative purposes, over a longer two-week period before and after a barrier breach. As we define a barrier breach to be any price reached above or below a given barrier level, the reaction windows we consider allow us to implicitly take account of false barrier breaches as we look to ascertain if patterns in price behaviour exist subsequent to barrier breaches. 


\subsection{Data description}

Front-month WTI (CME) and Brent (ICE) futures contracts are used for the analysis, representing the two key global benchmarks in the oil markets. The front-month contracts are used as they provide price information for the most actively traded contracts by volume. ${ }^{2}$ The analysis provides interesting insights into psychological barrier effects in oil futures trading. We distinguish between Brent and WTI contracts on the grounds that (i) recent evidence suggests that Brent has taken a lead position as the main global benchmark price reference in the crude oil markets and (ii) there is inherently greater complexity in determining fundamental value for Brent. This distinction in the crude oils will become apparent in the empirical discussions to come later. On point (i), Fattouh (2011) suggests that WTI is a broken benchmark and highlights the bottleneck issues that have prevailed around the Cushing storage point in recent years, which have resulted in prolonged periods of oversupply. The reasons set out for the bottleneck include the inaccessibility of the Cushing facilities to tanker or barge and the limited outflow pipeline network. Although the fundamental drivers of WTI prices are varied, the close link to inventory levels at Cushing has led in recent years to an oversupply based downward pressure on WTI prices, with the crude oil trading at a significant discount to Brent (Fattouh, 2011). Kao and Wan (2012) support this in their analysis and show that, amongst the many fundamental drivers of WTI prices, inventory levels at Cushing have a tangible influence. Indeed, Kao and Wan (2012) present evidence that WTI has failed to reflect market conditions due to this Cushing inventory effect, while they also propose that Brent has surpassed WTI as the leading reference price and has done so since 2004. Jin et al. (2012) demonstrate that Brent is responsive to global price shocks while WTI appears to be increasingly disconnected from such shocks. The has led to the emergence of Brent as the leading global benchmark in the crude oil markets with approximately $70 \%$ of all international trade being priced directly or indirectly off Brent (Fattouh, 2011). On point (ii), the complexity of Brent over WTI is reflected in the many more layers and financial instruments that exist within the Brent complex relative to the WTI pricing system (Fattouh, 2011).

Given this dislocation between WTI and Brent, the (locational) spread between these two major crude oils is also considered within the data set. This allows for an investigation into psychological barriers in the relative prices between these two key benchmarks. The price differential between WTI and Brent is closely monitored by oil market participants. Over the past number of years, a steady widening of the spread has emerged, reflecting the arguments set out above in relation to WTI and Brent; although more recently a gradual tightening of this spread has been seen again in the market. Table 1 provides descriptive statistics for the three data series.

\section{Empirical results}

To begin the empirical analysis, Fig. 1 presents a radar chart of the 10s frequency distribution for WTI and Brent, while Fig. 2 presents a radar chart of the 1s frequency distribution for WTI, Brent and the WTI-Brent spread. It is quite clear from both plots that the $10 \mathrm{~s}$ and $1 \mathrm{~s}$ frequency distributions do not conform to the uniform distribution. So informally it would appear that price clustering may be a feature.

To examine this formally, the barrier tests set out in Section 2.1 are performed. Specifically, barrier proximity and barrier kurtosis tests are

\footnotetext{
${ }^{2}$ The futures contract with the largest open interest would likely reflect the contract with the most professional trader interest. The contract with highest open interest is typically the front-month contract and so this contract in general represents the highest levels of both volume and open interest. It is important to emphasise that the results of this paper relate to last day rolled front-month futures prices for WTI and Brent and do not span the entire WTI and Brent futures curves or indeed the broader complex of physical and financial WTI and Brent prices. Such considerations are deferred for future research as set out in the conclusion.
}

applied to the WTI, Brent and WTI-Brent spread series, with 10s and 1s psychological barriers being considered for the price series and $1 \mathrm{~s}$ psychological barriers only for the spread series. The three barrier ranges defined in Section 1, i.e. $B R^{1} \equiv\{98,99,00,01,02\}, B R^{2} \equiv\{95$, $\ldots, 00, \ldots, 05\}$ and $B R^{3} \equiv\{90, \ldots, 00, \ldots, 10\}$, are considered for the barrier proximity testing. Tables 2 and 3 report the barrier proximity and barrier kurtosis results respectively; significant results at the 1\%,5\% and 10\% levels are bolded for convenience. From the barrier proximity results, there is evidence of price clustering effects around the $10 \mathrm{~s}$ psychological barriers for WTI in the case of all three barrier ranges. Indeed, the evidence suggests that the frequency of the barrier range digits is higher than the digits outside these regions by approximately 18,19 and 14 observations for $B R^{1}, B R^{2}$ and $B R^{3}$ respectively. In addition to this, for the third barrier region, there is evidence of price clustering effects around the 10s barriers. The frequency of the barrier range digits in this case is higher than the digits outside the region by approximately 6 observations. In general, there is no evidence of $1 \mathrm{~s}$ barriers price clustering for any of the series considered. Only in the case of the WTI-Brent spread, and only for the second barrier region, do price clustering effects emerge around the $1 \mathrm{~s}$ barriers. The evidence points to a lower frequency of observations in this case of approximately 6 observations. From the barrier kurtosis tests, it can be seen that a statistically significant $\gamma$ is reported for both WTI and Brent around the 10s psychological barriers. Indeed, the positive coefficient values provide evidence of price clustering for both crude oils.

Motivated by the price clustering evidence set out above, tests of conditional effects are next performed to determine whether there are differential reactions in the lead up to and subsequent to barrier breaches and whether these barrier breaches occur from above, i.e. due to falling prices, or from below, i.e. due to rising prices. The tests implemented are as described in Section 2.2. For WTI and Brent, \$10 barrier levels are considered over the range $\$ 10-\$ 140$, which spans the price levels achieved over the sample period. For the WTI-Brent spread series, $\$ 1$ barrier levels are considered over the range $(-\$ 27)-(+\$ 6)$, which spans the observed spread series. The negative barrier levels reflect the significant premium at which Brent has been trading to WTI over recent months. All barrier breaches are recorded and then the dummy variables $B D B_{t}^{n}, A D B_{t}^{n}, B U B_{t}^{n}$, $A U B_{t}^{n}$ are constructed as set out in Section 2.2. To test for the market reaction to barrier breaches, we consider the range of reaction windows $n=1$, 2, 3, 4, 5 and 10 days, which allows us to assess the speed of market reaction over and up to the week before and the week after a barrier breach but also, for comparative purposes, over a longer two-week period before and after a barrier breach. Fig. 3 provides histograms for the price levels at which barrier breaches occur, where the histogram bins have been centred on the respective $\$ 10$ and $\$ 1$ barrier levels. Table 4 provides a summary count of the downward and upward barrier breaches for sub-sample blocks of the data. Table 5 gives the results of the tests of conditional effects on WTI and Brent, while Table 6 provides the results for the WTI-Brent spread. Significant results at the 1\%, 5\% and $10 \%$ levels are again bolded for convenience.

Of most interest in the findings is the market reaction after a barrier breach, whether from above or from below. Hence, the coefficients for the $A D B_{t}^{n}$ and $A U B_{t}^{n}$ dummy variables provide important insights. It is

Table 1

Data descriptive statistics.

\begin{tabular}{llll}
\hline & WTI & Brent & WTI-Brent spread \\
\hline Units & $\$ /$ bbl & $\$ /$ bbl & $\$ /$ bbl \\
Start date & $11 / 10 / 1990$ & $11 / 10 / 1990$ & $11 / 10 / 1990$ \\
End date & $10 / 10 / 2012$ & $10 / 10 / 2012$ & $10 / 10 / 2012$ \\
Mean & 42.81 & 43.04 & -0.24 \\
Std Dev & 29.3905 & 32.4088 & 5.0882 \\
Skew & 1.0348 & 1.1268 & -3.0300 \\
Kurt & 2.9579 & 3.0697 & 11.8781 \\
Max & 145.29 & 146.08 & 6.53 \\
Min & 10.72 & 9.64 & -27.88 \\
\hline
\end{tabular}




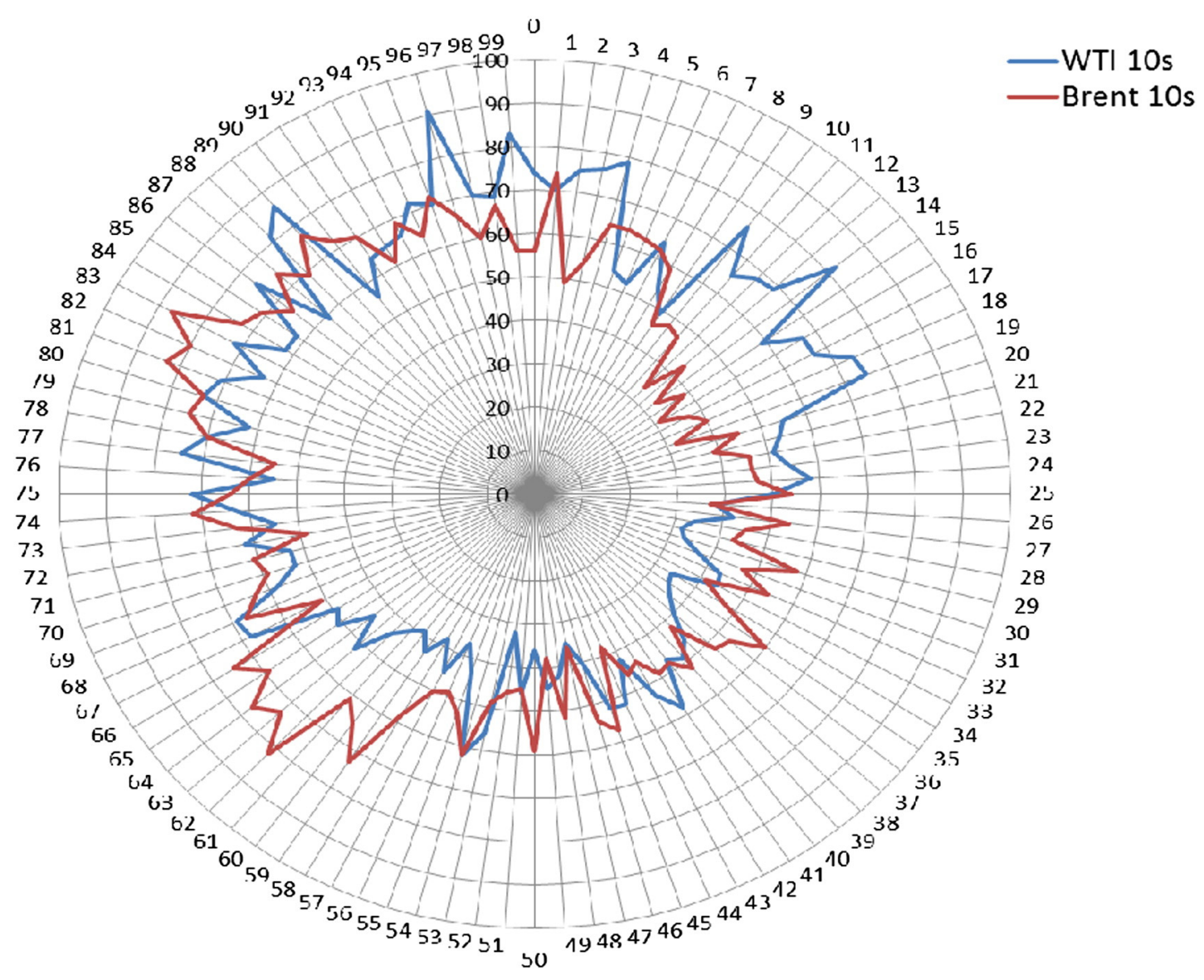

Fig. 1. 10s frequency distribution.

first noted that the greatest evidence for psychological barrier effects exists in the case of Brent, with some evidence for such effects in the case of WTI as well. In particular, for barrier breaches from above, Brent is shown to have a positive return effect on average over 2, 3, 4 and 5 days after the barrier breach, with no such evidence over the longer 10-day window. For WTI, a similar positive return effect is only seen for the case of the 3-day reaction window. So when barriers are breached from falling prices, the response of prices appears to be to rise again on average. For barrier breaches from below, Brent again shows evidence of psychological barrier effects with statistically significant results emerging for all reaction windows, even the longer 10-day reaction window. WTI also appears to show increased evidence of psychological barrier effects in the case of barrier breaches from below. Market reactions are evidenced over the 3-, 4-, 5- and 10-day reaction windows. Notably, Brent and WTI are both shown to have on average negative return effects. So it appears that barrier breaches from rising prices tend on average to lead to falling prices subsequently.

Overall we find evidence for psychological barrier effects in both Brent and WTI prices, although more evidence emerges from the testing framework for Brent. This potentially points to the differences between the two crude oils in terms of their positions as global price benchmarks and the complexity of their respective pricing systems, as set out in Section 2.3. We return to this notion in the next section, where we reexamine the differences between WTI and Brent within the context of the more statistically rigorous multiple hypothesis testing framework.

For the WTI-Brent spread series, the results set out in Table 6 show evidence as well of psychological barrier effects around the $\$ 1$ barrier levels. In particular, conditional effects can be seen to exist consistently across the 2-, 3-, 4-, 5- and 10-day reaction windows and for both barrier breaches from rising and from falling spread levels. Indeed, the signs of the reported coefficients for the $A D B_{t}^{n}$ and $A U B_{t}^{n}$ dummy variables are consistent with the WTI and Brent price analysis above. The resulting psychological barrier effects from falling and rising spreads mirror those of falling and rising oil prices.

The sample period considered in this study spans the years from 1990 to 2012. The dynamics of the crude oil market changed significantly over this two-decade period. In particular, from 2006 up to 2008 crude oil prices experienced an unprecedented bull market run, with prices continuously reaching new record highs until 2008 when prices had reached levels just below $\$ 150$ per barrel. Of course, in 2008 and leading into 2009, oil prices were seen to collapse back down to levels ultimately under $\$ 40$ per barrel, driven by the credit crisis and the resulting global economic downturn that emerged. In recent years prices have gradually ticked back upwards to levels around the $\$ 80, \$ 90$ and, more recently, $\$ 100$ mark. In view of this, the analysis above is extended by reanalysing psychological barriers effects for two sub-sample periods: 1990-2006 and 2007-2012. This allows us to consider whether there are differences in psychological barrier effects between the pre-credit crisis period of 1990-2006 and the credit crisis period from 2007 onwards. The results of the tests of conditional effects for these two sub-sample periods are provided in Appendix A. Significant results at the $1 \%, 5 \%$ and $10 \%$ levels are again bolded for convenience.

For the pre-2007 period, it can be seen that there is evidence from the testing, which suggests that when barrier breaches occur due to falling prices then prices tend to rise again on average. This is true for Brent over the 3-, 4-, 5- and 10-day reaction windows and for WTI only for the 3-day reaction window. Likewise, there is evidence for Brent and WTI that when $\$ 10$ barriers are breached with rising prices 


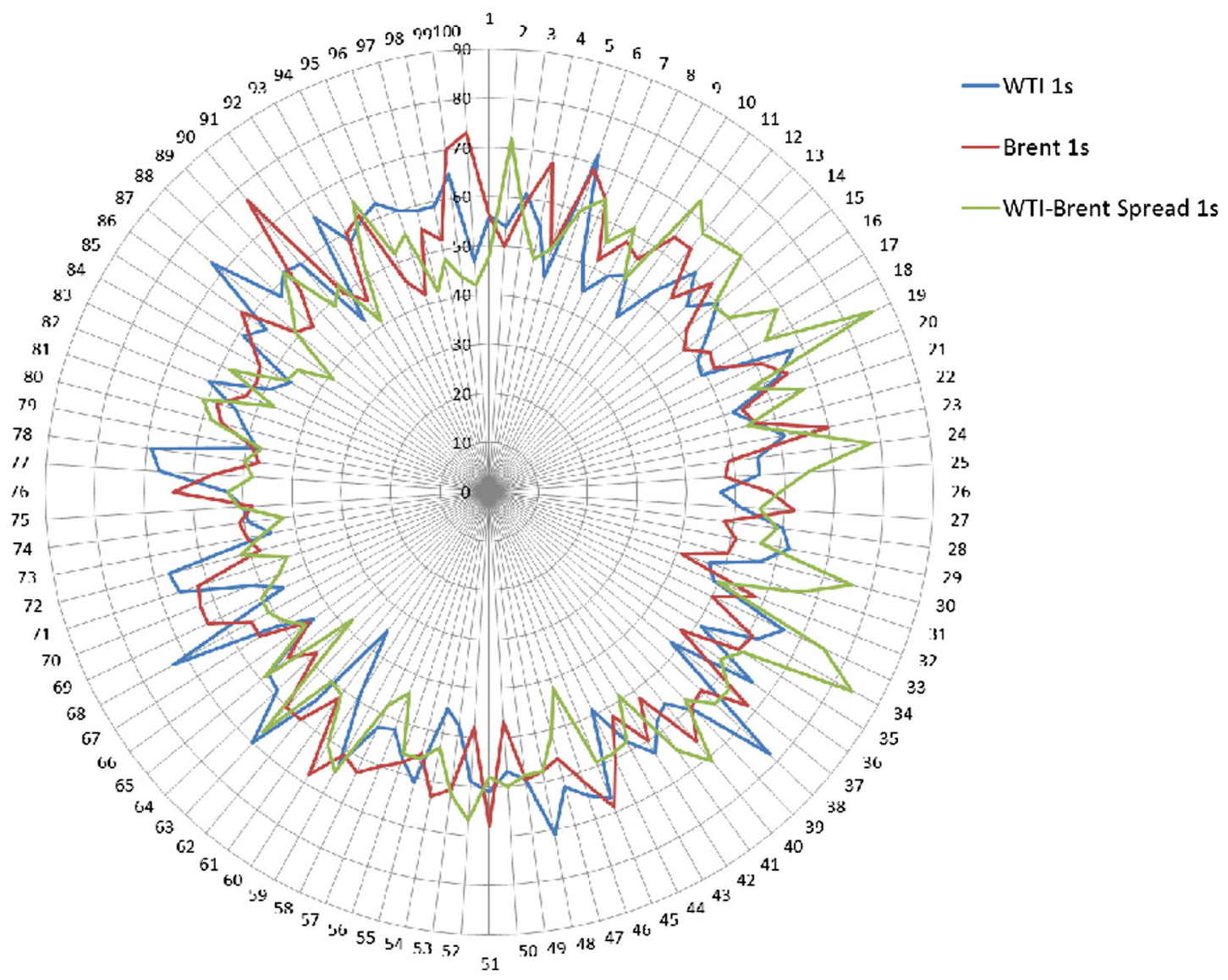

Fig. 2. 1s frequency distribution.

that prices tend to fall on average. For the WTI-Brent spread, similar barrier effects are shown to exist for almost all reaction windows considered. However, in complete contrast to these results that point

Table 2

Barrier proximity tests.

\begin{tabular}{|c|c|c|c|c|c|c|}
\hline \multirow[t]{2}{*}{ Contract } & \multicolumn{3}{|l|}{$10 \mathrm{~s}$} & \multicolumn{3}{|l|}{$1 \mathrm{~s}$} \\
\hline & $\beta$ & p-value & $R^{2}$ & $\beta$ & p-value & $R^{2}$ \\
\hline \multicolumn{7}{|c|}{ Barrier Range 1: $\{98,99,00,01,02\}$} \\
\hline WTI & 18.484 & 0.005 & 0.079 & -0.032 & 0.993 & 0.000 \\
\hline Brent & 3.958 & 0.510 & 0.004 & 5.221 & 0.114 & 0.025 \\
\hline WTI-Brent spread & $\mathrm{N} / \mathrm{A}$ & $\mathrm{N} / \mathrm{A}$ & $\mathrm{N} / \mathrm{A}$ & -4.421 & 0.322 & 0.010 \\
\hline \multicolumn{7}{|c|}{ Barrier range $2:\{95,96, \ldots, 04,05\}$} \\
\hline WTI & 19.199 & 0.000 & 0.176 & 1.029 & 0.688 & 0.002 \\
\hline Brent & 6.022 & $\overline{0.149}$ & 0.021 & 2.243 & 0.332 & 0.010 \\
\hline WTI-Brent spread & $\mathrm{N} / \mathrm{A}$ & $\mathrm{N} / \mathrm{A}$ & $\mathrm{N} / \mathrm{A}$ & -5.781 & 0.061 & 0.035 \\
\hline \multicolumn{7}{|c|}{ Barrier range 3: $\{90,91, \ldots, 09,10\}$} \\
\hline WTI & 14.440 & 0.000 & 0.169 & -1.340 & 0.495 & 0.005 \\
\hline Brent & 6.423 & $\overline{0.044}$ & 0.041 & 0.817 & 0.646 & 0.002 \\
\hline WTI-Brent spread & $\mathrm{N} / \mathrm{A}$ & N/A & $\mathrm{N} / \mathrm{A}$ & -3.291 & 0.167 & 0.019 \\
\hline
\end{tabular}

Barrier proximity test is $f(M)=\alpha+\beta D^{i}+\varepsilon$, where $f(M)$ is the absolute frequency of digits. $M$ is the set of all digits $\{0, \ldots, 99\}$. Three barrier ranges are defined as follows: $B R^{1} \equiv\{98,99$, $00,01,02\}, B R^{2} \equiv\{95, \ldots, 00, \ldots, 05\}$ and $B R^{3} \equiv\{90, \ldots, 00, \ldots, 10\}$, all of which are centred on 00 . Each of the defined barriers is then represented by a dummy variable, $D^{i}, i=1,2,3$, taking a value of 1 for digits in the barrier range and 0 otherwise. 10s digits refers to the two digits in a price bracketing the decimal point, and 1s digits refers to the two digits to the immediate right of the decimal point. Under the null of no barriers $\beta$ will be zero, whereas the presence of barriers will result in a higher frequency of M-values at the barrier and thus $\beta$ will be positive and significant. Results significant at the traditional $1 \%, 5 \%$ and $10 \%$ significance levels are bolded for emphasis, while results significant under the more statistically robust multiple hypothesis testing framework (see Section 4) are underlined. to psychological barrier effects in the pre-2007 period, when one moves to the post-2006 sample, no such evidence emerges for either crude oil and indeed for the spread. It appears that during this period in the oil markets, traditional psychological barriers that previously featured, dissipated away entirely during the bear market retreat following the credit crisis. This evidence suggests that the oil markets were driven by the economic bust and that in reverting back to global economy focused fundamentals, the influence of psychological barrier effects on oil futures prices receded. This aligns with the findings of De Zwart et al. (2009) who argue that when markets are strongly driven

Table 3

Barrier kurtosis tests.

\begin{tabular}{|c|c|c|c|c|c|c|}
\hline \multirow[t]{2}{*}{ Contract } & \multicolumn{3}{|l|}{$10 \mathrm{~s}$} & \multicolumn{3}{|l|}{$1 \mathrm{~s}$} \\
\hline & $\gamma$ & p-value & $R^{2}$ & $\gamma$ & p-value & $R^{2}$ \\
\hline WTI & 0.014 & 0.000 & 0.557 & 0.000 & 0.671 & 0.009 \\
\hline Brent & 0.004 & $\overline{0.004}$ & 0.432 & 0.000 & 0.823 & 0.006 \\
\hline WTI-Brent spread & $\mathrm{N} / \mathrm{A}$ & $\mathrm{N} / \mathrm{A}$ & $\mathrm{N} / \mathrm{A}$ & -0.001 & 0.211 & 0.291 \\
\hline
\end{tabular}

Barrier kurtosis test is $f(M)=\alpha+\varphi M+\gamma M^{2}+\varepsilon$, where $f(M)$ is the absolute frequency of digits. $M$ is the set of all digits $\{0, \ldots, 99\} .10$ s digits refers to the two digits in a price bracketing the decimal point, and $1 \mathrm{~s}$ digits refers to the two digits to the immediate right of the decimal point. If there is no abnormal distribution shape around barrier points then the coefficient of $\gamma$ should have a value of 0 , while the presence of an abnormal barriers shape would be suggested by a significant negative coefficient and clustering would be shown in a significant positive coefficient. Results significant at the traditional $1 \%, 5 \%$ and $10 \%$ significance levels are bolded for emphasis, while results significant under the more statistically robust multiple hypothesis testing framework (see Section 4) are underlined. 
(a)

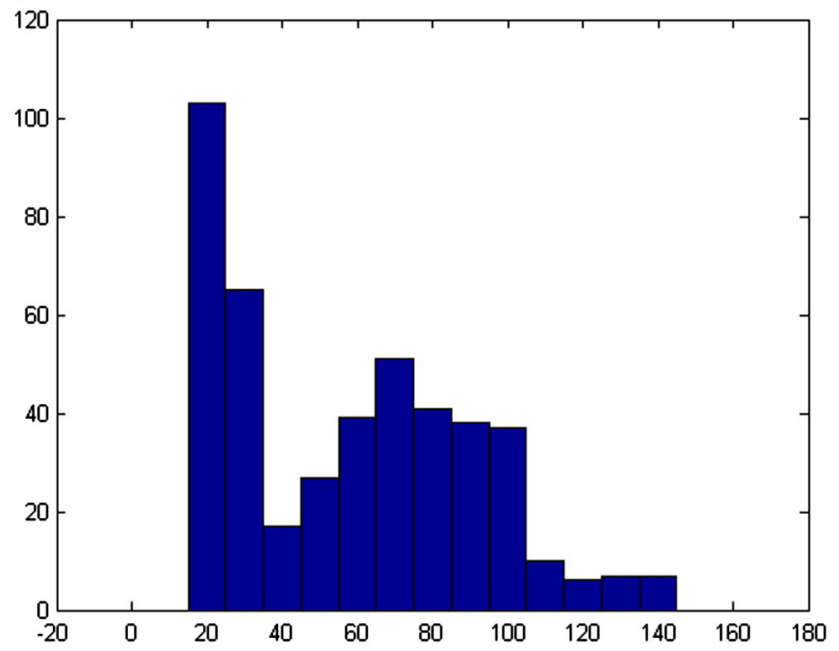

(b)

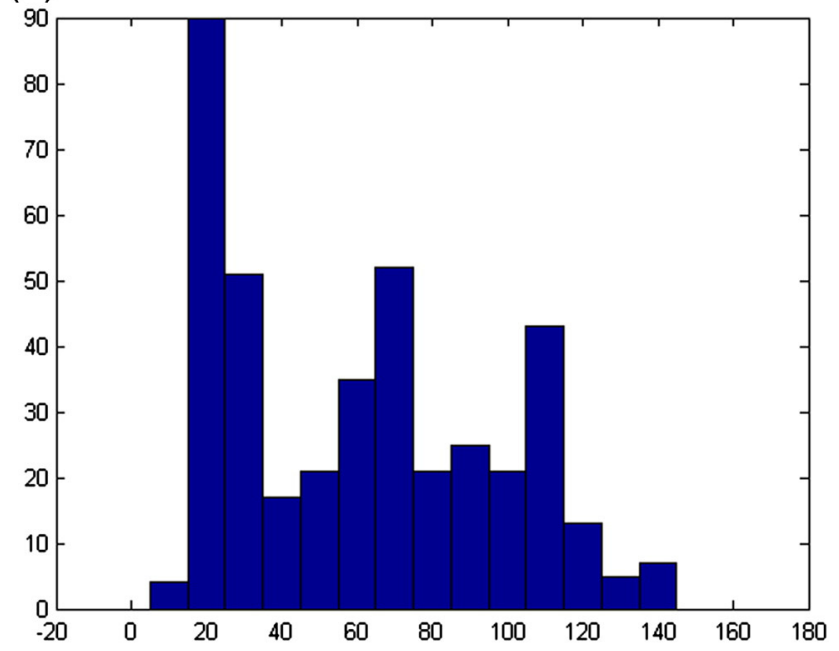

(c)

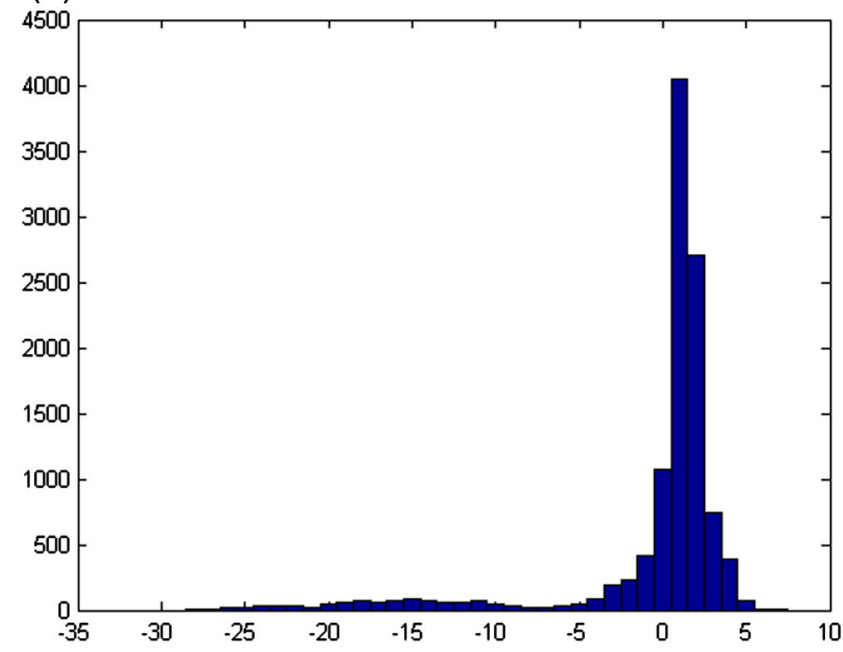

Fig. 3. Barrier breaches: histogram of price levels.

by fundamentals, as during the 2007-2012 oil market, traders tend to switch to fundamental pricing models, leaving minimal scope for influence from psychological barriers.

\section{Multiple comparisons problem}

At this juncture, we raise an important limitation of the testing conducted thus far. In particular, it is noted that the range of testing performed amounts to a large scale multiple hypothesis testing exercise. Specifically, between all of the barrier tests and the tests of conditional effects conducted on the full sample and the two sub-samples, a total of 369 coefficient hypothesis tests are performed. This introduces the well-established multiple comparisons problem. The multiple comparisons problem may lead to the identification of statistically significant results by pure chance alone when performing multiple hypothesis tests simultaneously. Without controlling for the multiple comparisons problem, the probability of rejecting true hypotheses, i.e. making false discoveries, is increased. Romano et al. (2010) provide a detailed exposition of the issues pertaining to multiple hypothesis testing (MHT), outlining the key literature in the area and in particular a range of generalised MHT techniques that have been developed recently to control for the multiple comparisons problem. This problem is well addressed in the scientific and medical fields but is largely overlooked in empirical finance, including the energy finance literature. Cummins (2013a) presents the argument to control for the multiple comparison problem via generalised MHT procedures within the context of analysing EU Emissions Trading Scheme market interactions. Cummins (2013b) uses similar techniques for analysing interactions between emissions and energy markets. Cummins and Bucca (2012) examine the quantitative trading of oil market spreads, using generalised MHT techniques to robustly evaluate the performance of statistical arbitrage trading strategies.

By way of motivation for the reader, consider a simple experiment, as per Romano et al. (2010), whereby $n=100$ simultaneous hypothesis tests are performed, all of which are assumed to be true. Taking a significance level of $\alpha=5 \%$, one would expect five of the true hypotheses to be rejected. More importantly, if all hypothesis tests are mutually independent then the probability of rejecting at least one true null hypothesis - a concept commonly referred to as the familywise error rate - is given by the very high level of $1-(1-\alpha)^{n}=1-0.95^{100}=$ 0.994 . Indeed, even if the hypothesis tests are not mutually independent then it is still possible to place an upper bound on the familywise error rate, given by $\min (n \times \alpha, 1)$.

Several techniques have been developed to control for this problem. The literature has evolved over recent decades, and in particular over recent years, towards more generalised procedures that offer the advantage of greater power over earlier procedures, where power is loosely defined, as in Romano et al. (2010), as the ability to reject a null hypothesis when it is false. Earlier procedures in the literature suffer from excessive conservativeness, in the sense that in attempting to control for false discoveries such procedures make it very difficult to identify true discoveries (i.e. rejection of false null hypotheses). Recent generalised procedures seek to relax this constraint and so increase the power of the testing. A suite of such techniques will be described next, which will be applied to the empirical analysis presented so far.

\subsection{Generalised familywise error rate techniques}

Before introducing the generalised concept, first note that the familywise error rate (FWER) is defined as the probability that at least one or more false discoveries occur. Consistent with the notation of Romano et al. (2010), the following definition is made:

$F W E R \equiv P\left\{\right.$ reject at least one null hypothesis $\left.H_{0, i}: i \in I\right\}$,

where $H_{0, i}, i=1, \ldots, s$, is a set of null hypotheses $(s \geq 1)$ and $I$ is the set of true null hypotheses. So the FWER describes the probability of making 
Table 4

Barrier breach count for sub-sample blocks.

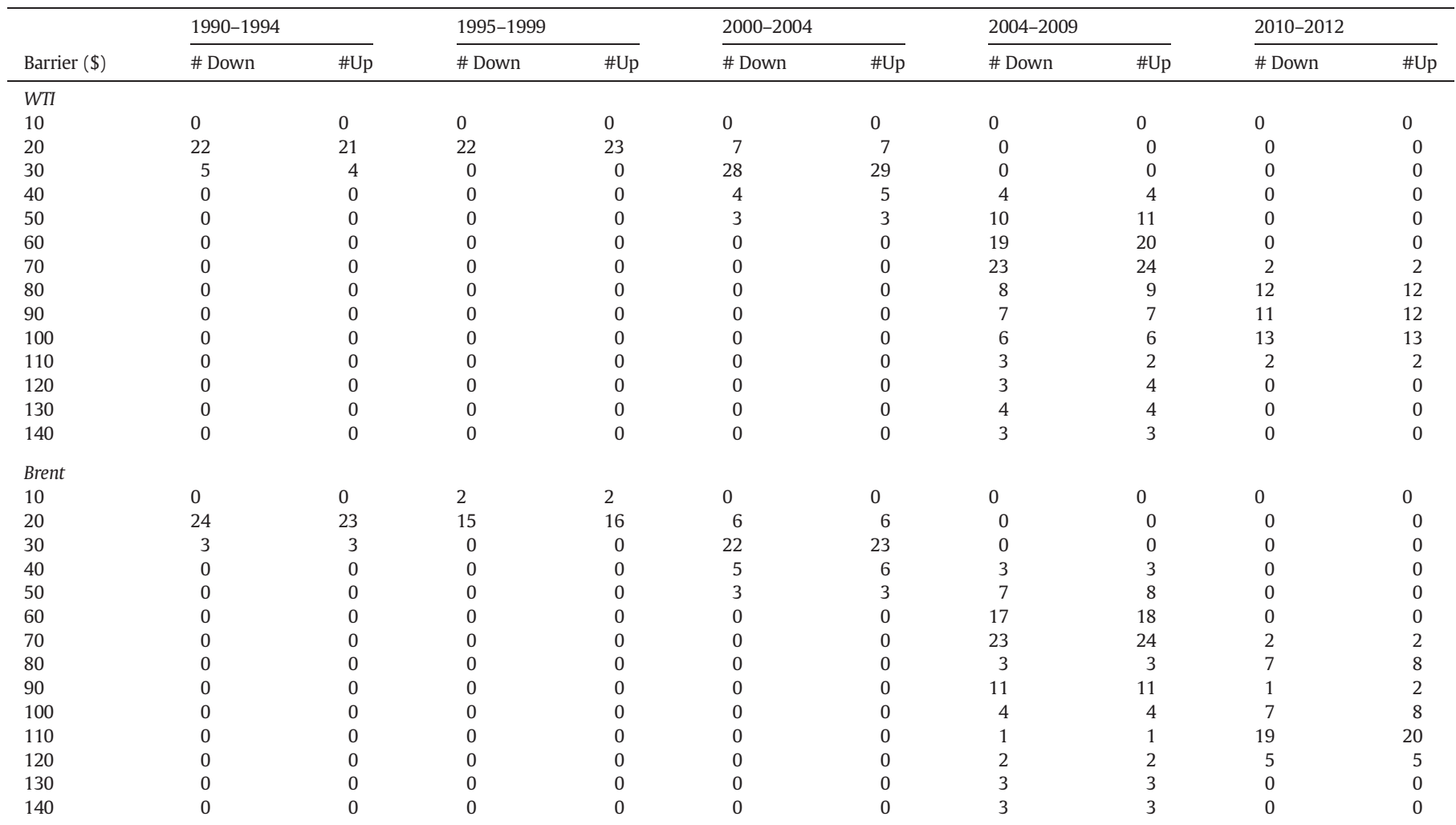

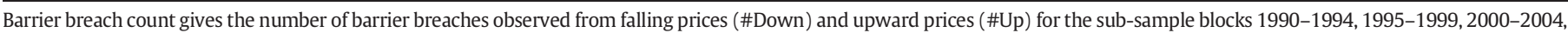
2005-2009 and 2010-2012. A barrier breach to be any price reached above or below a given barrier level.

at least one false discovery. Controlling the FWER involves setting a significance level $\alpha$ and requiring that FWER $\leq \alpha$. This approach is particularly conservative and so as a result is criticised for lacking power. The greater the total number of hypotheses $s$, the more difficult it is to make true discoveries.

To deal with these weaknesses, the concept of the generalised FWER has been considered in the literature more recently. The generalised FWER seeks to control for $k$ (where $k \geq 1$ ) or more false discoveries and, in so doing, allows for greater power in MHT applications. The generalised $k$-FWER is defined as follows:

$k-F W E R \equiv P\left\{\right.$ reject at least $k$ null hypothesis $\left.H_{0, i}: i \in I\right\}$.

Controlling the $k$-FWER involves setting a significance level $\alpha$ and requiring that $k-$ FWER $\leq \alpha$. The choice of $k$ is set by the user and the greater this choice then the greater the power in identifying true discoveries, at the expense of potentially making more false discoveries along the way. See Romano et al. (2010) for a full discussion.

Given the availability of p-values from the hypothesis testing, pvalue based MHT procedures are used to control for the multiple comparisons problem in our study. Two specific procedures are used and these are described below. For this, consider the hypotheses $H_{0,(i)}, i=$ $1, \ldots, s$, ordered from the most significant down to the least significant, i.e. where the $\mathrm{p}$-values are such that $\hat{p}_{(1)} \leq \hat{p}_{(2)} \ldots \leq \hat{p}_{(s)}{ }^{3}$

\footnotetext{
${ }^{3}$ A subtle difference in notation is introduced here. $H_{0, j}$ is the $i$-th hypothesis test considered and $\hat{p}_{i}$ is the associated p-value. In contrast, $H_{0,(i)}$ is used to denote the $i$-th hypothesis when all hypotheses are ordered in terms of significance from the most significant up to the least significant, with $\hat{p}_{(i)}$ denoting the associated ordered p-value.
}

\subsubsection{Generalised Bonferroni (GB)}

The generalised Bonferroni method is defined by Romano et al. (2010) whereby the significance level is adjusted such that hypothesis $H_{0,(i)}, i=1, \ldots, s$, is deemed rejected if and only if

$\hat{p}_{(i)} \leq \alpha_{(i)} \equiv k \cdot \alpha / s$.

This procedure has the advantage of being robust to the dependence structure of the hypothesis tests.

\subsubsection{Generalised Holm (GH)}

Extends the single step nature of the GB methodology to a superior stepwise one (Romano et al., 2010). Lehmann and Romano (2005) propose a generalisation of Holm (1979) with the following set of cutoff values for comparison against the ordered p-values $\hat{p}_{(i)}$ :

$\alpha_{(i)} \equiv\left\{\begin{array}{cc}\frac{k \alpha}{s}, & i \leq k \\ \frac{k \alpha}{s+k-i}, & i>k\end{array}\right.$

This procedure is again robust to the dependence structure of the hypothesis tests, with the additional advantage that the stepwise nature of the procedure offers greater power over single step methods.

\subsection{Empirical results revisited}

In light of the discussion above, we revisit the empirical results reported in Section 3 and apply both the GB and GH methods to control 
Table 5

Tests of conditional effects (OLS): WTI and Brent.

\begin{tabular}{|c|c|c|c|c|c|c|c|c|c|c|c|c|}
\hline \multirow{2}{*}{$\frac{\text { Reaction Wdw ( } n \text { days })}{\text { Contract }}$} & \multicolumn{2}{|l|}{1} & \multicolumn{2}{|l|}{2} & \multicolumn{2}{|l|}{3} & \multicolumn{2}{|l|}{4} & \multicolumn{2}{|l|}{5} & \multicolumn{2}{|l|}{10} \\
\hline & WTI & Brent & WTI & Brent & WTI & Brent & WTI & Brent & WTI & Brent & WTI & Brent \\
\hline Constant & $\begin{array}{c}0.0004 \\
(0.2804)\end{array}$ & $\begin{array}{c}0.0005 \\
(0.1511)\end{array}$ & $\begin{array}{c}0.0004 \\
(0.2117)\end{array}$ & $\begin{array}{c}0.0003 \\
(0.2862)\end{array}$ & $\begin{array}{c}0.0006 \\
(0.0760)\end{array}$ & $\begin{array}{c}0.0004 \\
(0.2157)\end{array}$ & $\begin{array}{c}0.0007 \\
(0.0452)\end{array}$ & $\begin{array}{c}0.0004 \\
(0.2356)\end{array}$ & $\begin{array}{c}0.0007 \\
(0.0503)\end{array}$ & $\begin{array}{c}0.0005 \\
(0.1842)\end{array}$ & $\begin{array}{c}0.0007 \\
(0.1156)\end{array}$ & $\begin{array}{c}0.0005 \\
(0.1668)\end{array}$ \\
\hline$R_{t-1}$ & $\begin{array}{r}-0.0003 \\
(0.9806)\end{array}$ & $\begin{array}{r}-0.0127 \\
(0.3728)\end{array}$ & $\begin{array}{c}0.0044 \\
(0.7529)\end{array}$ & $\begin{array}{r}-0.0169 \\
(0.2217)\end{array}$ & $\begin{array}{c}0.0068 \\
(0.6171)\end{array}$ & $\begin{array}{r}-0.0214 \\
(0.1164)\end{array}$ & $\begin{array}{c}0.0018 \\
(0.8932)\end{array}$ & $\begin{array}{r}-0.0204 \\
(0.1331)\end{array}$ & $\begin{array}{c}0.0022 \\
(0.8713)\end{array}$ & $\begin{array}{r}-0.0198 \\
(0.1436)\end{array}$ & $\begin{array}{l}0.0000 \\
0.9981\end{array}$ & $\begin{array}{r}-0.0240 \\
0.0731\end{array}$ \\
\hline$B D B_{t}^{n}$ & $\begin{array}{c}-0.0021 \\
(0.1995)\end{array}$ & $\begin{array}{c}0.0000 \\
(0.9861)\end{array}$ & $\begin{array}{c}-0.0005 \\
(0.6630)\end{array}$ & $\begin{array}{c}0.0005 \\
(0.7104)\end{array}$ & $\begin{array}{c}-0.0003 \\
(0.8066)\end{array}$ & $\begin{array}{c}0.0020 \\
(0.0587)\end{array}$ & $\begin{array}{c}-0.0004 \\
(0.6776)\end{array}$ & $\begin{array}{c}0.0016 \\
(0.1199)\end{array}$ & $\begin{array}{c}0.0009 \\
(0.3734)\end{array}$ & $\begin{array}{c}0.0015 \\
(0.1267)\end{array}$ & $\begin{array}{c}0.0013 \\
(0.1448)\end{array}$ & $\begin{array}{c}0.0010 \\
(0.2798)\end{array}$ \\
\hline$B U B_{t}^{n}$ & $\begin{array}{r}-0.0008 \\
(0.6115)\end{array}$ & $\begin{array}{r}-0.0009 \\
(0.5528)\end{array}$ & $\begin{array}{r}-0.0037 \\
(\underline{0.0022})\end{array}$ & $\begin{array}{r}-0.0010 \\
(0.4083)\end{array}$ & $\begin{array}{r}-0.0036 \\
(0.0007)\end{array}$ & $\begin{array}{r}-0.0037 \\
(\mathbf{0 . 0 0 0 5 )}\end{array}$ & $\begin{array}{r}-0.0026 \\
(0.0091)\end{array}$ & $\begin{array}{r}-0.0033 \\
(\underline{0.0010)}\end{array}$ & $\begin{array}{r}-0.0028 \\
(0.0034)\end{array}$ & $\begin{array}{r}-0.0033 \\
(\underline{0.0006)}\end{array}$ & $\begin{array}{r}-0.0020 \\
(0.0256)\end{array}$ & $\begin{array}{r}-0.0016 \\
(0.0815)\end{array}$ \\
\hline$A D B_{t}^{n}$ & $\begin{array}{r}-0.0010 \\
(0.5697)\end{array}$ & $\begin{array}{c}0.0004 \\
(0.8022)\end{array}$ & $\begin{array}{c}\overline{0.0020} \\
(0.1056)\end{array}$ & $\begin{array}{c}0.0022 \\
(0.0857)\end{array}$ & $\begin{array}{c}\overline{0.0025} \\
(0.0205)\end{array}$ & $\begin{array}{c}\overline{0.0020} \\
(0.0733)\end{array}$ & $\begin{array}{c}0.0010 \\
(0.3157)\end{array}$ & $\begin{array}{c}\overline{0.0026} \\
(0.0136)\end{array}$ & $\begin{array}{c}\overline{0.0011} \\
(0.2594)\end{array}$ & $\begin{array}{r}\overline{0.0031} \\
(0.0020) \\
\end{array}$ & $\begin{array}{c}0.0009 \\
(0.3064)\end{array}$ & $\begin{array}{c}0.0014 \\
(0.1458)\end{array}$ \\
\hline$A U B_{t}^{n}$ & $\begin{array}{r}-0.0016 \\
(0.3352)\end{array}$ & $\begin{array}{r}-0.0066 \\
(0.0001)\end{array}$ & $\begin{array}{r}-0.0014 \\
(0.2516)\end{array}$ & $\begin{array}{r}-0.0037 \\
(\underline{0.0028)}\end{array}$ & $\begin{array}{r}-0.0028 \\
(0.0087)\end{array}$ & $\begin{array}{r}-\mathbf{0 . 0 0 2 2} \\
(0.0382)\end{array}$ & $\begin{array}{c}-0.0019 \\
(0.0530)\end{array}$ & $\begin{array}{c}-0.0023 \\
(0.0250)\end{array}$ & $\begin{array}{c}-0.0023 \\
(0.0147)\end{array}$ & $\begin{array}{r}-\overline{0.0028} \\
(\underline{0.0044)}\end{array}$ & $\begin{array}{r}-0.0017 \\
(0.0513)\end{array}$ & $\begin{array}{r}-0.0019 \\
(0.0398)\end{array}$ \\
\hline
\end{tabular}

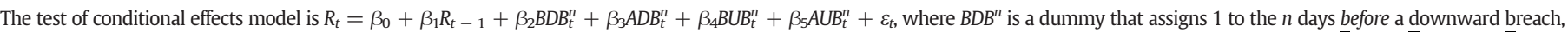

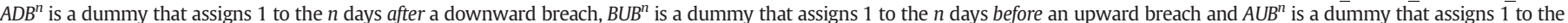

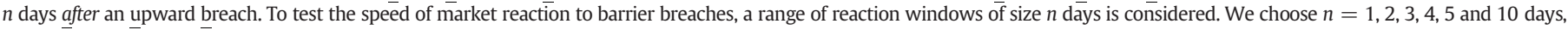

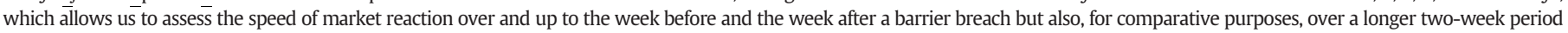

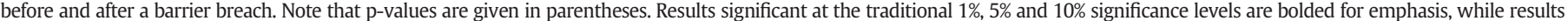
significant under the more statistically robust multiple hypothesis testing framework (see Section 4) are underlined.

for the multiple comparisons problem. As noted earlier, a total of 369 coefficient hypothesis tests are performed between the various barrier and conditional effects tests. For the GB and GH implementations, we set the generalising parameter $k=\lfloor 369 \times 5 \%\rfloor=18$, such that no more than $5 \%$ of the tests represent false discoveries. We control the generalised familywise error rate $k$-FWER at the three statistical significance levels of $\alpha=1 \%, 5 \%$ and $10 \%$. Under the single step GB method, these significance levels lead to respective adjusted cut-off values of $0.00049,0.00244$ and 0.00488 . So, for example, if we control the generalised familywise error rate at the $\alpha=5 \%$ level then we will only consider a result to be statistically significant if the associated p-value is less than 0.00244 . The GH method with its stepwise construction aligns exactly with the GB method for the first 18 ordered hypothesis tests and then recursively adjusts the cut-off values upwards for all hypothesis tests from position 19 onwards. As it turns out, the GB and GH methods as applied in this study lead to the exact same conclusions to be drawn and so, for ease of exposition, we just focus on the single step GB for the discussion hereafter.
Returning to the barrier test results in Tables 2 and 3 and the tests of conditional effects in Tables 5 and 6, we re-evaluate the results by applying the three GB cut-off values $0.00049,0.00244$ and 0.00488 that respectively correspond to the $1 \%, 5 \%$ and $10 \%$ significance levels for the generalised familywise error rate. Test results significant at these significance levels are highlighted in the tables by the p-values that are underlined. With this MHT procedure applied, the empirical story that emerges is quite different but is one that is far more robust in statistical terms in its control of the multiple comparison problem. In particular, the evidence for psychological barriers is much reduced in this set up but is evidence in which we may have greater statistical confidence, thereby we mitigate the potential for false inferences.

Taking first the barrier proximity tests of Table 2, it can be seen that price clustering appears to only now be a feature for WTI and only for the two barrier ranges $B R^{2}$ and $B R^{3}$. However in contrast, from Table 3, the positive coefficient values $\gamma$ that provide evidence of price clustering for both WTI and Brent around the 10s psychological barriers are shown

Table 6

Tests of conditional effects (OLS): WTI-Brent spread.

\begin{tabular}{|c|c|c|c|c|c|c|}
\hline Reaction Wdw ( $n$ days) & 1 & 2 & 3 & 4 & 5 & 10 \\
\hline Constant & $\begin{array}{c}-0.0082 \\
(0.3718)\end{array}$ & $\begin{array}{r}-0.0049 \\
(0.6259)\end{array}$ & $\begin{array}{c}0.0014 \\
(0.8976)\end{array}$ & $\begin{array}{c}0.0002 \\
(0.9893)\end{array}$ & $\begin{array}{c}0.0011 \\
(0.9301)\end{array}$ & $\begin{array}{c}0.0086 \\
(0.6055)\end{array}$ \\
\hline$R_{t-1}$ & $\begin{array}{r}-0.0645 \\
(0.0004)\end{array}$ & $\begin{array}{r}-0.0469 \\
(0.0017)\end{array}$ & $\begin{array}{r}-0.0562 \\
(0.0001)\end{array}$ & $\begin{array}{r}-0.0561 \\
(0.0000)\end{array}$ & $\begin{array}{r}-0.0545 \\
(0.0001)\end{array}$ & $\begin{array}{r}-0.0670 \\
(0.0000)\end{array}$ \\
\hline$B D B_{t}^{n}$ & $\begin{array}{c}0.0335 \\
(0.1214)\end{array}$ & $\begin{array}{c}0.0429 \\
(0.0114)\end{array}$ & $\begin{array}{c}0.0424 \\
(0.0080)\end{array}$ & $\begin{array}{c}0.0524 \\
(0.0011)\end{array}$ & $\begin{array}{c}0.0593 \\
(0.0003)\end{array}$ & $\begin{array}{r}0.0881 \\
(0.0000)\end{array}$ \\
\hline$B U B_{t}^{n}$ & $\begin{array}{c}-0.0217 \\
(0.3214)\end{array}$ & $\begin{array}{r}-0.0577 \\
(0.0007)\end{array}$ & $\begin{array}{c}-0.0637 \\
(0.0001)\end{array}$ & $\begin{array}{r}-\overline{0.0663} \\
(0.0000)\end{array}$ & $\begin{array}{r}-0.0729 \\
(0.0000)\end{array}$ & $\begin{array}{r}-\overline{0.1034} \\
(0.0000)\end{array}$ \\
\hline$A D B_{t}^{n}$ & $\begin{array}{c}0.0165 \\
(0.5124)\end{array}$ & $\begin{array}{c}\overline{0.0591} \\
(0.0011)\end{array}$ & $\begin{array}{c}0.0465 \\
(0.0050)\end{array}$ & $\begin{array}{c}\overline{0.0590} \\
(0.0003)\end{array}$ & $\begin{array}{c}\overline{0.0853} \\
(0.0000)\end{array}$ & $\begin{array}{c}\overline{0.0913} \\
(0.0000)\end{array}$ \\
\hline$A U B_{t}^{n}$ & $\begin{array}{r}-0.0007 \\
(0.9779)\end{array}$ & $\begin{array}{r}-\overline{0.0456} \\
(0.0130)\end{array}$ & $\begin{array}{r}-\overline{0.0452} \\
(0.0068)\end{array}$ & $\begin{array}{r}-\overline{0.0585} \\
(\mathbf{0 . 0 0 0 4 )}\end{array}$ & $\begin{array}{r}-\overline{0.0855} \\
(0.0000)\end{array}$ & $\begin{array}{r}-\overline{0.0951} \\
(0.0000)\end{array}$ \\
\hline
\end{tabular}

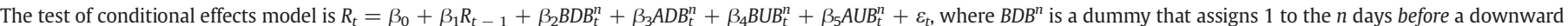

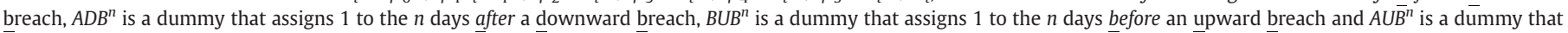

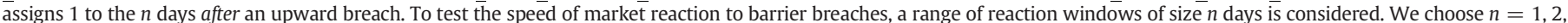

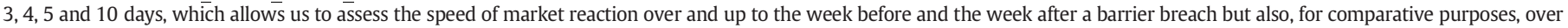

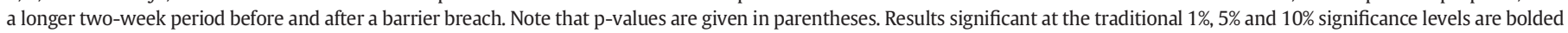
for emphasis, while results significant under the more statistically robust multiple hypothesis testing framework (see Section 4) are underlined. 
to hold under the MHT framework. Turning to the tests of conditional effects set out in Tables 5 and 6 , it can be seen that much of the evidence for psychological barriers effects falls away with the application of the GB procedure. In particular, it can be seen that the previously identified evidence around barrier breaches from falling prices for both WTI and Brent does not hold. Indeed, it is only for the 5-day reaction window that we see any evidence hold for Brent. In contrast, the evidence around barrier breaches from rising prices holds much better under the MHT framework, which allows us to conclude with more statistical confidence that when such upward breaches occur then prices tend on average to fall subsequently. However, it is notable that this only occurs for Brent and not for WTI. Indeed, psychological barrier effects emerge for Brent under the GB procedure for the 1-, 2- and 5-day reaction windows. So, under our statistically robust MHT framework, it emerges that there are significant psychological barrier effects for Brent that we do not see with WTI. This is where we appeal to the distinction identified between Brent and WTI in Section 2.3 in terms of their positions as global benchmarks and the complexity of their respective pricing systems. There is growing evidence to support the emergence of Brent as the leading global crude oil price benchmark and the deterioration of WTI in this important referencing role. As identified earlier, Fattouh (2011) suggests that WTI has broken down as a global benchmark and rationalises this with particular reference to the outflow bottleneck issues that have prevailed around Cushing in recent years, constraints which have led to an oversupply based downward pressure on WTI prices and trading at a significant discount to its counterpart, Brent (Fattouh, 2011). Kao and Wan (2012) support this view and argue that amongst the many fundamental drivers of WTI prices there is a close link between price and inventory levels at Cushing. Kao and Wan (2012) provide evidence that WTI has failed to reflect market conditions in recent years and indeed put forward the case that Brent has surpassed WTI as the leading reference price since 2004. Jin et al. (2012) similarly demonstrate that Brent is responsive to global price shocks while WTI appears to be increasingly disconnected. This leading benchmark role for Brent, with some $70 \%$ of all international trade being priced directly or indirectly off Brent (Fattouh, 2011), may explain the greater psychological barrier effects that we find in Brent futures prices.

Furthermore, the complexity of Brent over WTI is reflected in the many more layers and financial instruments that exist within the Brent pricing system, spanning dated Brent, Brent forwards, Contract for Differences (CfDs), Exchange for Physicals, and Brent futures, options and swaps (Fattouh, 2011). Drawing on recent advances in behavioural finance showing an increased role for psychological biases in more complex decisions (e.g. Dowling and Lucey, 2008; Yao and Li, 2013), we further argue that the greater complexity surrounding Brent fundamental value leads to a greater role for psychological barriers in the price formation for associated futures contracts.

To conclude, we turn our attention now to the psychological barrier effects in the WTI-Brent spread momentarily and then to the results of the sub-sample periods. For the WTI-Brent spread, it is notable that the $\$ 1$ barrier results hold particularly well under the GB implementation, with the downward barrier effects holding across all reaction windows and the upward barrier effects holding for the 4-, 5- and 10-day reaction windows under the MHT framework. For the results of the two sub-sample periods, similar conclusions emerge. Interestingly, for the more recent post-2006 period, none of the limited test results that were identified as significant under the traditional $1 \%, 5 \%$ and $10 \%$ levels hold under the GB procedure. For the earlier pre-2007 period, it can be seen again that in relation to downward barrier effects, evidence only holds for Brent over the 5-day reaction window. The evidence for upward barrier effects is stronger and holds for Brent across all reaction windows considered.

\section{Conclusion}

This paper significantly extends the prior testing of psychological barriers in professionally traded markets through a number of theoretical and testing advances that offer novel perspectives on how these psychological barriers are likely to influence oil futures prices. Focusing on $\$ 10$ barrier regions (movements through a price ending in a 0 dollar digit), we show evidence of the existence of such psychological barriers. We show that psychological barriers only appear to influence prices in the pre-credit crisis period of 1990-2006 and that such psychological barrier effects dissipated subsequently during the bust in oil prices over the later years of the last decade, at which point the global recession took hold and markets reverted to wider economy focused fundamentals. Significant focus is also placed on determining the speed of market reaction to barrier breaches and our findings suggest significant market reaction up to 5 trade days (and in some cases up to 10 trade days) subsequent to breaching psychological barriers. With psychological barrier effects emerging with much greater statistical confidence in the case of Brent, we appeal to recent arguments that Brent has overtaken WTI as the dominant global benchmark for crude oil prices. It is further argued that the greater complexity around Brent fundamental value leads to a greater role for psychological barriers in prices for these contracts. This aligns with recent behavioural finance showing an increased role for psychological biases in more complex decisions.

There are a number of issues related to these findings that could be explored in future research. In particular, a determination of how traders switch between fundamentally-driven behaviour and (partially) psychologically-influenced behaviour, as suggested by our sub-period analysis, would provide an important extension. There is also the issue of how psychological barriers extend out to the wider oil price complex. For example, whether there is an expectation of differential behaviour in Brent forward contracts compared to Brent futures or indeed in dated Brent compared to Brent futures. Further research could fruitfully investigate similar psychological barrier effects in other professionally traded energy and commodity markets. The multiple hypothesis testing framework we employ offers the potential for statistical rigour in this specific future work, while providing an impetus to explicitly account for the multiple comparisons problem in empirical-based energy and commodity market studies more generally.

\section{Acknowledgments}

The authors would like the thank the participants of the $51 \mathrm{st}$ Meeting of the Euro Working Group on Commodities and Financial Modelling and 1st Conference of the Research Centre for Energy Management \& the International Centre for Shipping, Trade and Finance, whose feedback and comments have significantly improved the paper. We would like to extend a special word of thanks to Chloe Le Coq for her insightful recommendations. The authors would also like to thank the participants of the 61st Meeting of the Midwest Finance Association and in particular the feedback and comments of Marc Kramer and Werner DeBondt. The authors would finally like to thank the two anonymous reviewers who reviewed this manuscript for their astute comments and recommendations, which have served to enhance the paper considerably.

\section{References}

Acharya, V.V., Lochstoer, L.A., Ramadorai, T., 2013. Limits to arbitrage and hedging evidence from commodity markets. J. Financ. Econ. 109 (2), 441-465.

Aggarwal, R., Lucey, B.M., 2007. Psychological barriers in gold prices? Rev. Financ. Econ $16,217-230$.

Bentzen, J., 2007. Does OPEC influence crude oil prices? Testing for co-movements and causality between regional crude oil prices. Appl. Econ. 39, 1375-1385 
Appendix A. Tests of conditional effects: subsamples

Table 7

Tests of conditional effects (OLS): pre-2007.

\begin{tabular}{|c|c|c|c|c|c|c|c|c|c|c|c|c|}
\hline \multirow{2}{*}{$\begin{array}{l}\text { Reaction Wdw ( } n \text { days }) \\
\text { Contract }\end{array}$} & \multicolumn{2}{|l|}{1} & \multicolumn{2}{|l|}{2} & \multicolumn{2}{|l|}{3} & \multicolumn{2}{|l|}{4} & \multicolumn{2}{|l|}{5} & \multicolumn{2}{|l|}{10} \\
\hline & WTI & Brent & WTI & Brent & WTI & Brent & WTI & Brent & WTI & Brent & WTI & Brent \\
\hline Constant & $\begin{array}{l}0.0002 \\
(0.5118)\end{array}$ & $\begin{array}{l}0.0003 \\
(0.3568)\end{array}$ & $\begin{array}{l}0.0003 \\
(0.4273)\end{array}$ & $\begin{array}{l}0.0002 \\
(0.5482)\end{array}$ & $\begin{array}{l}0.0004 \\
(0.2782)\end{array}$ & $\begin{array}{l}0.0003 \\
(0.4413)\end{array}$ & $\begin{array}{l}0.0004 \\
(0.2660)\end{array}$ & $\begin{array}{l}0.0002 \\
(0.5198)\end{array}$ & $\begin{array}{l}0.0005 \\
(0.2388)\end{array}$ & $\begin{array}{l}0.0003 \\
(0.3805)\end{array}$ & $\begin{array}{l}0.0002 \\
(0.6315)\end{array}$ & $\begin{array}{l}0.0003 \\
(0.4275)\end{array}$ \\
\hline$R_{t-1}$ & $\begin{array}{l}0.0223 \\
(0.1724)\end{array}$ & $\begin{array}{l}-0.0014 \\
(0.9327)\end{array}$ & $\begin{array}{l}0.0258 \\
(0.1080)\end{array}$ & $\begin{array}{l}-0.0037 \\
(0.8146)\end{array}$ & $\begin{array}{l}0.0306 \\
(0.0537)\end{array}$ & $\begin{array}{l}-0.0048 \\
(0.7612)\end{array}$ & $\begin{array}{l}0.0234 \\
(0.1358)\end{array}$ & $\begin{array}{c}-0.0058 \\
(0.7104)\end{array}$ & $\begin{array}{l}0.0250 \\
(0.1115)\end{array}$ & $\begin{array}{l}-0.0010 \\
(0.9497)\end{array}$ & $\begin{array}{l}0.0221 \\
(0.1553)\end{array}$ & $\begin{array}{c}-0.0093 \\
(0.5500)\end{array}$ \\
\hline$B D B_{t}^{n}$ & $\begin{array}{l}-0.0041 \\
(0.0604)\end{array}$ & $\begin{array}{l}0.0039 \\
(0.0807)\end{array}$ & $\begin{array}{c}-0.0003 \\
(0.8602)\end{array}$ & $\begin{array}{l}0.0029 \\
(0.0813)\end{array}$ & $\begin{array}{l}0.0006 \\
(0.6845)\end{array}$ & $\begin{array}{l}0.0046 \\
(0.0018)\end{array}$ & $\begin{array}{l}0.0009 \\
(0.4775)\end{array}$ & $\begin{array}{l}0.0045 \\
(0.0014)\end{array}$ & $\begin{array}{l}0.0015 \\
(0.2339)\end{array}$ & $\begin{array}{l}0.0047 \\
(0.0007)\end{array}$ & $\begin{array}{l}0.0030 \\
(0.0087)\end{array}$ & $\begin{array}{l}0.0033 \\
(0.0114)\end{array}$ \\
\hline$B U B_{t}^{n}$ & $\begin{array}{l}0.0003 \\
(0.8919)\end{array}$ & $\begin{array}{l}0.0015 \\
(0.4806)\end{array}$ & $\begin{array}{c}-0.0041 \\
(0.0102)\end{array}$ & $\begin{array}{l}0.0007 \\
(0.6684)\end{array}$ & $\begin{array}{l}-0.0034 \\
(0.0139)\end{array}$ & $\begin{array}{l}-0.0042 \\
(0.0044)\end{array}$ & $\begin{array}{l}-0.0025 \\
(0.0582)\end{array}$ & $\begin{array}{l}-0.0037 \\
(0.0074)\end{array}$ & $\begin{array}{l}-0.0027 \\
(0.0314)\end{array}$ & $\begin{array}{l}-0.0050 \\
(0.0002)\end{array}$ & $\begin{array}{l}-0.0024 \\
(0.0364)\end{array}$ & $\begin{array}{c}-0.0026 \\
(0.0404)\end{array}$ \\
\hline$A D B_{t}^{n}$ & $\begin{array}{l}-0.0005 \\
(0.8279)\end{array}$ & $\begin{array}{l}-0.0030 \\
(0.1832)\end{array}$ & $\begin{array}{l}0.0024 \\
(0.1515)\end{array}$ & $\begin{array}{l}0.0012 \\
(0.5000)\end{array}$ & $\begin{array}{l}0.0033 \\
(0.0215)\end{array}$ & $\begin{array}{l}0.0030 \\
(0.0478)\end{array}$ & $\begin{array}{l}0.0008 \\
(0.5632)\end{array}$ & $\begin{array}{l}0.0032 \\
(0.0238)\end{array}$ & $\begin{array}{l}0.0015 \\
(0.2373)\end{array}$ & $\begin{array}{l}0.0059 \\
(0.0000)\end{array}$ & $\begin{array}{l}0.0018 \\
(0.1305)\end{array}$ & $\begin{array}{l}0.0031 \\
(0.0191)\end{array}$ \\
\hline$A U B_{t}^{n}$ & $\begin{array}{l}-0.0009 \\
(0.6939)\end{array}$ & $\begin{array}{l}-0.0111 \\
(0.0000)\end{array}$ & $\begin{array}{l}-0.0015 \\
(0.3678)\end{array}$ & $\begin{array}{c}-0.0069 \\
(0.0000)\end{array}$ & $\begin{array}{l}-0.0042 \\
(0.0030)\end{array}$ & $\begin{array}{c}-0.0056 \\
(0.0001)\end{array}$ & $\begin{array}{l}-0.0024 \\
(0.0750)\end{array}$ & $\begin{array}{c}-0.0052 \\
(0.0002)\end{array}$ & $\begin{array}{l}-0.0031 \\
(0.0127)\end{array}$ & $\begin{array}{l}-0.0073 \\
(0.0000)\end{array}$ & $\begin{array}{c}-0.0026 \\
(0.0204)\end{array}$ & $\begin{array}{l}-0.0046 \\
(0.0003)\end{array}$ \\
\hline
\end{tabular}

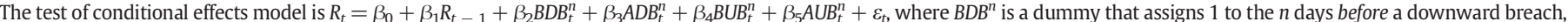

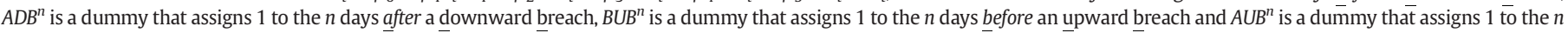

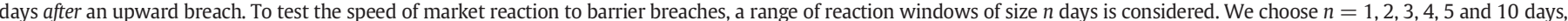

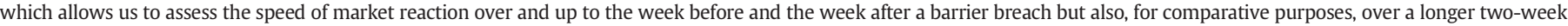

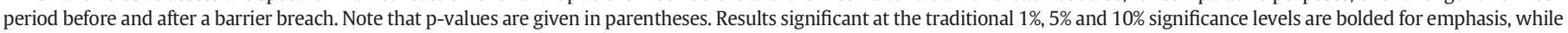
results significant under the more statistically robust multiple hypothesis testing framework (see Section 4) are underlined.

Table 8

Tests of conditional effects (OLS): post-2006.

\begin{tabular}{|c|c|c|c|c|c|c|c|c|c|c|c|c|}
\hline \multirow{2}{*}{$\frac{\text { Reaction Wdw ( } n \text { days) }}{\text { Contract }}$} & \multicolumn{2}{|l|}{1} & \multicolumn{2}{|l|}{2} & \multicolumn{2}{|l|}{3} & \multicolumn{2}{|l|}{4} & \multicolumn{2}{|l|}{5} & \multicolumn{2}{|l|}{10} \\
\hline & WTI & Brent & WTI & Brent & WTI & Brent & WTI & Brent & WTI & Brent & WTI & Brent \\
\hline Constant & $\begin{array}{l}0.0008 \\
(0.3000)\end{array}$ & $\begin{array}{l}0.0009 \\
(0.1858)\end{array}$ & $\begin{array}{l}0.0010 \\
(0.2316)\end{array}$ & $\begin{array}{l}0.0008 \\
(0.2416)\end{array}$ & $\begin{array}{l}0.0016 \\
(0.0777)\end{array}$ & $\begin{array}{l}0.0010 \\
(0.2120)\end{array}$ & $\begin{array}{l}0.0021 \\
(0.0252)\end{array}$ & $\begin{array}{l}0.0011 \\
(0.1603)\end{array}$ & $\begin{array}{l}0.0020 \\
(0.0393)\end{array}$ & $\begin{array}{l}0.0010 \\
(0.2344)\end{array}$ & $\begin{array}{l}0.0032 \\
(0.0087)\end{array}$ & $\begin{array}{l}0.0019 \\
(0.0841)\end{array}$ \\
\hline$R_{t-1}$ & $\begin{array}{l}-0.0531 \\
(0.0725)\end{array}$ & $\begin{array}{l}-0.0464 \\
(0.1121)\end{array}$ & $\begin{array}{l}-0.0458 \\
(0.1010)\end{array}$ & $\begin{array}{l}-0.0571 \\
(0.0381)\end{array}$ & $\begin{array}{l}-0.0477 \\
(0.0786)\end{array}$ & $\begin{array}{l}-0.0720 \\
(0.0079)\end{array}$ & $\begin{array}{l}-0.0477 \\
(0.0743)\end{array}$ & $\begin{array}{l}-0.0666 \\
(0.0139)\end{array}$ & $\begin{array}{l}-0.0494 \\
(0.0626)\end{array}$ & $\begin{array}{l}-0.0717 \\
(0.0072)\end{array}$ & $\begin{array}{l}-0.0534 \\
(0.0407)\end{array}$ & $\begin{array}{l}-0.0684 \\
(0.0094)\end{array}$ \\
\hline$B D B_{t}^{n}$ & $\begin{array}{l}-0.0004 \\
(0.8713)\end{array}$ & $\begin{array}{l}-0.0043 \\
(0.0804)\end{array}$ & $\begin{array}{l}-0.0013 \\
(0.5193)\end{array}$ & $\begin{array}{l}-0.0024 \\
(0.2044)\end{array}$ & $\begin{array}{l}-0.0017 \\
(0.3171)\end{array}$ & $\begin{array}{l}-0.0009 \\
(0.5866)\end{array}$ & $\begin{array}{l}-0.0025 \\
(0.1230)\end{array}$ & $\begin{array}{l}-0.0017 \\
(0.2709)\end{array}$ & $\begin{array}{l}-0.0004 \\
(0.8248)\end{array}$ & $\begin{array}{l}-0.0015 \\
(0.3189)\end{array}$ & $\begin{array}{l}-0.0016 \\
(0.3120)\end{array}$ & $\begin{array}{l}-0.0013 \\
(0.3551)\end{array}$ \\
\hline$B U B_{t}^{n}$ & $\begin{array}{l}-0.0023 \\
(0.3765)\end{array}$ & $\begin{array}{l}-0.0038 \\
(0.1102)\end{array}$ & $\begin{array}{l}-0.0034 \\
(0.0800)\end{array}$ & $\begin{array}{l}-0.0031 \\
(0.0892)\end{array}$ & $\begin{array}{l}-0.0041 \\
(0.0177)\end{array}$ & $\begin{array}{l}-0.0037 \\
(0.0212)\end{array}$ & $\begin{array}{l}-0.0034 \\
(0.0339)\end{array}$ & $\begin{array}{l}-0.0033 \\
(0.0262)\end{array}$ & $\begin{array}{l}-0.0036 \\
(0.0221)\end{array}$ & $\begin{array}{l}-0.0023 \\
(0.1123)\end{array}$ & $\begin{array}{l}-0.0029 \\
(0.0695)\end{array}$ & $\begin{array}{l}-0.0019 \\
(0.1839)\end{array}$ \\
\hline$A D B_{t}^{n}$ & $\begin{array}{l}-0.0023 \\
(0.4089)\end{array}$ & $\begin{array}{l}0.0038 \\
(0.1550)\end{array}$ & $\begin{array}{l}0.0011 \\
(0.6025)\end{array}$ & $\begin{array}{l}0.0030 \\
(0.1248)\end{array}$ & $\begin{array}{l}0.0013 \\
(0.4622)\end{array}$ & $\begin{array}{l}0.0007 \\
(0.6791)\end{array}$ & $\begin{array}{l}0.0011 \\
(0.5173)\end{array}$ & $\begin{array}{l}0.0016 \\
(0.3035)\end{array}$ & $\begin{array}{l}0.0006 \\
(0.7064)\end{array}$ & $\begin{array}{l}0.0004 \\
(0.7759)\end{array}$ & $\begin{array}{l}0.0003 \\
(0.8733)\end{array}$ & $\begin{array}{l}0.0002 \\
(0.8816)\end{array}$ \\
\hline$A U B_{t}^{n}$ & $\begin{array}{l}-0.0017 \\
(0.5473)\end{array}$ & $\begin{array}{l}-0.0019 \\
(0.4473)\end{array}$ & $\begin{array}{l}-0.0011 \\
(0.5904)\end{array}$ & $\begin{array}{l}-0.0002 \\
(0.9298)\end{array}$ & $\begin{array}{l}-0.0014 \\
(0.4433)\end{array}$ & $\begin{array}{l}0.0015 \\
(0.3682)\end{array}$ & $\begin{array}{l}-0.0017 \\
(0.3095)\end{array}$ & $\begin{array}{l}0.0008 \\
0.6166\end{array}$ & $\begin{array}{l}-0.0017 \\
0.2731\end{array}$ & $\begin{array}{l}0.0015 \\
0.3086\end{array}$ & $\begin{array}{l}-0.0012 \\
0.4524\end{array}$ & $\begin{array}{l}0.0001 \\
0.9528\end{array}$ \\
\hline
\end{tabular}

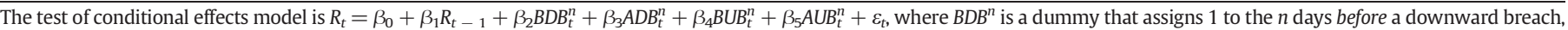

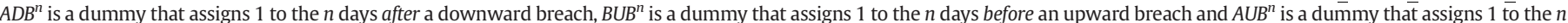

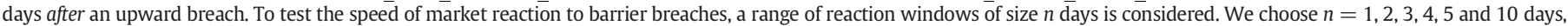

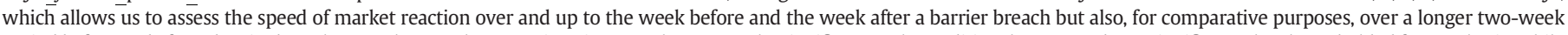

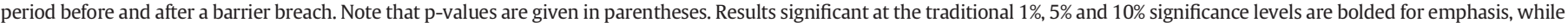
results significant under the more statistically robust multiple hypothesis testing framework (see Section 4 ) are underlined.

Table 9

Tests of conditional effects (OLS): WTI-Brent spread pre-2007.

\begin{tabular}{|c|c|c|c|c|c|c|}
\hline Reaction Wdw ( $n$ days) & 1 & 2 & 3 & 4 & 5 & 10 \\
\hline Constant & $\begin{array}{l}-0.0072 \\
(0.2796)\end{array}$ & $\begin{array}{l}-0.0032 \\
(0.6549)\end{array}$ & $\begin{array}{c}-0.0023 \\
(0.7711)\end{array}$ & $\begin{array}{c}-0.0041 \\
(0.6188)\end{array}$ & $\begin{array}{c}-0.0015 \\
(0.8620)\end{array}$ & $\begin{array}{l}0.0076 \\
(0.5070)\end{array}$ \\
\hline$R_{t-1}$ & $\begin{array}{l}-0.1074 \\
(0.0000)\end{array}$ & $\begin{array}{l}-0.0806 \\
(0.0000)\end{array}$ & $\begin{array}{l}-0.0935 \\
(0.0000)\end{array}$ & $\begin{array}{c}-0.0942 \\
(0.0000)\end{array}$ & $\begin{array}{l}-0.0961 \\
(0.0000)\end{array}$ & $\begin{array}{l}-0.1123 \\
(0.0000)\end{array}$ \\
\hline$B D B_{t}^{n}$ & $\begin{array}{l}0.0580 \\
(0.0023)\end{array}$ & $\begin{array}{l}0.0705 \\
(0.0000)\end{array}$ & $\begin{array}{l}0.0699 \\
(0.0000)\end{array}$ & $\begin{array}{l}0.0737 \\
(0.0000)\end{array}$ & $\begin{array}{l}0.0829 \\
(0.0000)\end{array}$ & $\begin{array}{l}0.0951 \\
(0.0000)\end{array}$ \\
\hline$B U B_{t}^{n}$ & $\begin{array}{l}-0.0574 \\
(0.0024)\end{array}$ & $\begin{array}{l}-0.0701 \\
(0.0000)\end{array}$ & $\begin{array}{l}\overline{-0.0707} \\
(0.0000)\end{array}$ & $\begin{array}{l}-0.0628 \\
(0.0000)\end{array}$ & $\begin{array}{l}-0.0821 \\
(0.0000)\end{array}$ & $\begin{array}{c}-0.1084 \\
(0.0000)\end{array}$ \\
\hline$A D B_{t}^{n}$ & $\begin{array}{l}\overline{0.0494} \\
(0.0225)\end{array}$ & $\begin{array}{l}\overline{0.0732} \\
(\underline{0.0000)}\end{array}$ & $\begin{array}{l}\overline{0.0622} \\
(0.0000)\end{array}$ & $\begin{array}{l}\overline{0.0715} \\
(0.0000)\end{array}$ & $\begin{array}{l}\overline{0.0868} \\
(0.0000)\end{array}$ & $\begin{array}{l}0.0841 \\
(0.0000)\end{array}$ \\
\hline$A U B_{t}^{n}$ & $\begin{array}{l}0.0245 \\
(0.2593)\end{array}$ & $\begin{array}{l}-0.0564 \\
(0.0003)\end{array}$ & $\begin{array}{l}-0.0534 \\
(0.0001)\end{array}$ & $\begin{array}{l}-0.0704 \\
(0.0000)\end{array}$ & $\begin{array}{l}-0.0839 \\
(0.0000)\end{array}$ & $\begin{array}{l}-0.0829 \\
(0.0000)\end{array}$ \\
\hline
\end{tabular}

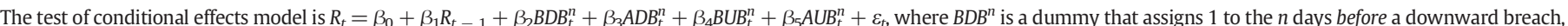

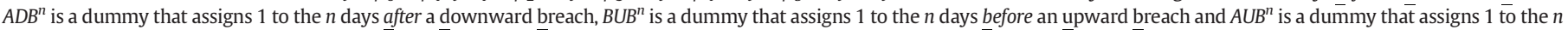

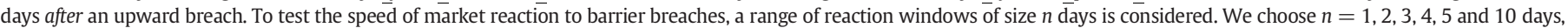

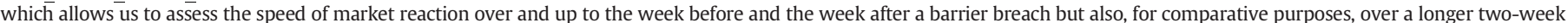

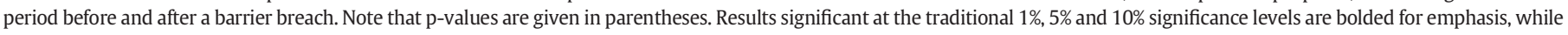
results significant under the more statistically robust multiple hypothesis testing framework (see Section 4 ) are underlined. 
Table 10

Tests of conditional effects (OLS): WTI-Brent spread post-2006.

\begin{tabular}{|c|c|c|c|c|c|c|}
\hline Reaction Wdw ( $n$ days) & 1 & 2 & 3 & 4 & 5 & 10 \\
\hline Constant & $\begin{array}{l}-0.0175 \\
(0.6266)\end{array}$ & $\begin{array}{l}-0.0238 \\
(0.5863)\end{array}$ & $\begin{array}{l}0.0116 \\
(0.8198)\end{array}$ & $\begin{array}{l}0.0113 \\
(0.8474)\end{array}$ & $\begin{array}{l}0.0016 \\
(0.9806)\end{array}$ & $\begin{array}{l}0.0095 \\
(0.9324)\end{array}$ \\
\hline$R_{t-1}$ & $\begin{array}{l}-0.0531 \\
(0.1813)\end{array}$ & $\begin{array}{l}-0.0359 \\
(0.2336)\end{array}$ & $\begin{array}{l}-0.0419 \\
(0.1368)\end{array}$ & $\begin{array}{l}-0.0423 \\
(0.1208)\end{array}$ & $\begin{array}{l}-0.0352 \\
(0.1891)\end{array}$ & $\begin{array}{l}-0.0453 \\
(0.0813)\end{array}$ \\
\hline$B U B_{t}^{n}$ & $\begin{array}{l}0.0426 \\
(0.4586)\end{array}$ & $\begin{array}{l}-0.0342 \\
(0.4658)\end{array}$ & $\begin{array}{l}-0.0555 \\
(0.2241)\end{array}$ & $\begin{array}{l}-0.0818 \\
(0.0860)\end{array}$ & $\begin{array}{l}-0.0524 \\
(0.3095)\end{array}$ & $\begin{array}{l}-0.0718 \\
(0.4036)\end{array}$ \\
\hline
\end{tabular}

The test of conditional effects model is $R_{t}=\beta_{0}+\beta_{1} R_{t-1}+\beta_{2} B D B_{t}^{n}+\beta_{3} A D B_{t}^{n}+\beta_{4} B U B_{t}^{n}+\beta_{5} A U B_{t}^{n}+\varepsilon_{t}$, where $B D B^{n}$ is a dummy that assigns 1 to the $n$ days before a downward breach, $A D B^{n}$ is a dummy that assigns 1 to the $n$ days after a downward breach, $B U B^{n}$ is a dummy that assigns 1 to the $n$ days before an upward breach and $A U B^{n}$ is a dummy that assigns 1 to the $n$ days after an upward breach. To test the speed of market reaction to barrier breaches, a range of reaction windows of size $n$ days is considered. We choose $n=1,2,3,4,5$ and 10 days, which allows us to assess the speed of market reaction over and up to the week before and the week after a barrier breach but also, for comparative purposes, over a longer two-week period before and after a barrier breach. Note that p-values are given in parentheses. Results significant at the traditional $1 \%, 5 \%$ and $10 \%$ significance levels are bolded for emphasis, while results significant under the more statistically robust multiple hypothesis testing framework (see Section 4) are underlined.

Bharati, R., Crain, S.J., Kaminski, V., 2012. Clustering in crude oil prices and the target pricing zone hypothesis. Energy Econ. 34, 1115-1123.

Bhattacharya, U., Holden, C.W., Jacobsen, S., 2012. Penny wise, dollar foolish: buy-sell imbalances on and around round numbers. Manag. Sci. 58, 413-431.

Coval, J.D., Shumway, T., 2005. Do behavioral biases affect prices? J. Financ. 60, 1-34.

Cummins, M., 2013a. EU ETS market interactions: the case for multiple hypothesis testing approaches. Appl. Energy 111, 701-709.

Cummins, M., 2013b. Multiple comparisons problem: recent advances applied to energy and emissions. Appl. Econ. Lett. 20, 903-909.

Cummins, M., Bucca, A., 2012. Quantitative spread trading in the crude oil and products markets. Quant. Financ. 12, 1857-1875.

De Zwart, G., Markwat, T., Swinkels, L., van Dijk, D., 2009. The economic value of fundamental and technical information in emerging currency markets. J. Int. Money Financ. 28 (4), 581-604.

DeLong, J., Shleifer, A., Summers, L., Waldmann, R., 1990. Noise trader risk in financial markets. J. Polit. Econ. 98, 703-715.

Dowling, M., Lucey, B.M., 2008. Robust global mood influences in equity pricing. J. Multinatl. Financ. Manag. 18 (2), 145-164.

Fattouh, B., 2007. WTI benchmark temporarily breaks down: it is really a big deal. Middle East Economic Survey, XLIX (20) (14 May).

Fattouh, B., 2009. Reinforcing feedbacks, time spreads and oil prices. Middle East Economic Survey, LII (17) (27 April).

Fattouh, B., 2010. The dynamics of crude oil price differentials. Energy Econ. 32, 334-342.

Fattouh, B., 2011. An Anatomy of Crude Oil Pricing. Working Paper. Oxford Institute of Energy Studies, University of Oxford.

Fattouh, B., Mahadeva, L., 2012. Assessing the Financialization Hypothesis. Oxford Institute for Energy Studies.

Fenton-O'Creevy, M., Soane, E., Nicholson, N., Willman, P., 2011. Thinking, feeling and deciding: the influence of emotions on the decision making and performance of traders. J. Organ. Behav. 32 (8), 1044-1061.

Froot, K., Arabadjis, J., Cates, S., Lawrence, S., 2011. How institutional investors frame their losses: evidence on dynamic loss aversion from currency portfolios. J. Portfolio Manag. 8 (1), 1-9.

Ghalayini, L., 2011. The interdependence of oil spot and futures markets. Eur. J. Econ. Financ. Adm. Sci. 32, 149-161.

Hache, E., Lantz, F., 2013. Speculative trading and oil price dynamic: a study of the WTI market. Energy Econ. 36, 334-340.
Hammoudeh, S., Ewing, B., Thompson, M., 2008. Threshold cointegration analysis of crude oil benchmarks. Energy J. 29, 79-95.

Holm, S., 1979. A simple sequentially rejective multiple test procedure. Scandinavian Journal of Statistics 6, 65-70.

Ikenberry, D.L., Weston, J.P., 2008. Clustering in US stock prices after decimalisation. Eur Financ. Manag. 14, 30-54.

Jin, X., Xiaowen Lin, S., Tamvakis, M., 2012. Volatility transmission and volatility impulse response functions in crude oil markets. Energy Econ. 34 (6), 2125-2134.

Kao, C.W., Wan, J.Y., 2012. Price discount, inventories and the distortion of WT benchmark. Energy Econ. 34 (1), 117-124.

Kaufmann, R.K., Ullman, B., 2009. Oil prices, speculation, and fundamentals: interpreting causal relations among spot and futures prices. Energy Econ. 31, 550-558.

Lehmann, E.L., Romano, J.P., 2005. Generalizations of the familywise error rate. Ann. Stat. 33, 1138-1154.

Mitchell, J., 2001. Clustering and psychological barriers: the importance of numbers. J Futur. Mark. 21, 395-428.

Narayan, P.K., Narayan, S., Popp, S., 2011. Investigating price clustering in the oil futures market. Appl. Energy 397-402.

O'Connell, P.G., Teo, M., 2009. Institutional investors, past performance, and dynamic loss aversion. J. Financ. Quant. Anal. 44, 155-188.

Palao, F., Pardo, A., 2012. Assessing price clustering in European carbon markets Appl. Energy 92, 51-56.

Panella, M., D'Ecclesia, R.L., Stack, D.G., Barcellona, F., 2014. Crude oil prices and kernel-based models. Int. J. Financ. Eng. Risk Manag. 1, 214-238.

Romano, J.P., Shaikh, A.M., Wolf, M., 2010. Hypothesis testing in econometrics. Ann. Rev. Econ. 2, 75-104.

Swierenga, J., 2012. Price discovery in European energy markets. Working Paper (available from: http://papers.ssrn.com/sol3/papers.cfm?abstract_id=2116194)

Tokic, T., 2011. Rational destabilizing speculation, positive feedback trading, and the oil bubble of 2008. Energy Policy 39, 2051-2061.

Westerhoff, F., 2003. Anchoring and psychological barriers in foreign exchange markets. J. Behav. Financ. 4, 65-70.

Yao, J., Li, D., 2013. Bounded rationality as a source of loss aversion and optimism: a study of psychological adaptation under incomplete information. J. Econ. Dyn. Control. 37 (1), 18-31. 